Article

\title{
Genome-Wide Association Study on Root System Architecture and Identification of Candidate Genes in Wheat (Triticum aestivum L.)
}

\author{
Jianhui Ma ${ }^{1}$, Dongyang Zhao ${ }^{1}$, Xiaoxiao Tang ${ }^{1}$, Meng Yuan ${ }^{1,2}$, Daijing Zhang ${ }^{1}$, Mengyuan Xu ${ }^{1}$, Yingze Duan ${ }^{1}$, \\ Haiyue Ren ${ }^{1}$, Qingdong Zeng ${ }^{2}$, Jianhui $\mathrm{Wu}^{2}$, Dejun Han ${ }^{2}$, Tian $\mathrm{Li}^{3, *}$ and Lina Jiang ${ }^{1, *}$
}

check for

updates

Citation: Ma, J.; Zhao, D.; Tang, X.; Yuan, M.; Zhang, D.; Xu, M.; Duan, Y.; Ren, H.; Zeng, Q.; Wu, J.; et al. Genome-Wide Association Study on Root System Architecture and Identification of Candidate Genes in Wheat (Triticum aestivum L.). Int. J. Mol. Sci. 2022, 23, 1843. https:// doi.org/10.3390/ijms23031843

Academic Editor: Anna M. Mastrangelo

Received: 8 January 2022

Accepted: 4 February 2022

Published: 6 February 2022

Publisher's Note: MDPI stays neutral with regard to jurisdictional claims in published maps and institutional affiliations.

Copyright: (C) 2022 by the authors. Licensee MDPI, Basel, Switzerland. This article is an open access article distributed under the terms and conditions of the Creative Commons Attribution (CC BY) license (https:// creativecommons.org/licenses/by/ $4.0 /)$.
1 College of Life Science, Henan Normal University, Xinxiang 453007, China; 2013033@htu.edu.cn (J.M.); zdyzhaoyang@163.com (D.Z.); hnsqtxx@163.com (X.T.); ym140906@163.com (M.Y.); 041160@htu.edu.cn (D.Z.); xumengyuan2022@163.com (M.X.); d1804114003@163.com (Y.D.); rhy20010621@163.com (H.R.)

2 State Key Laboratory of Crop Stress Biology for Arid Areas, Northwest A\&F University, Yangling, Xianyang 712100, China; zengqd@nwafu.edu.cn (Q.Z.); wujh@nwafu.edu.cn (J.W.); handj@nwsuaf.edu.cn (D.H.)

3 Key Laboratory of Crop Gene Resources and Germplasm Enhancement, Ministry of Agriculture, Institute of Crop Sciences, Chinese Academy of Agricultural Sciences, Beijing 100081, China

* Correspondence: litian@caas.cn (T.L.); jiangln@htu.edu.cn (L.J.)

\begin{abstract}
The root tissues play important roles in water and nutrient acquisition, environmental adaptation, and plant development. In this study, a diversity panel of 388 wheat accessions was collected to investigate nine root system architecture (RSA) traits at the three-leaf stage under two growing environments: outdoor pot culture (OPC) and indoor pot culture (IPC). Phenotypic analysis revealed that root development was faster under OPC than that under IPC and a significant correlation was observed between the nine RSA traits. The 660K single-nucleotide polymorphism (SNP) chip was used for a genome-wide association study (GWAS). Significant SNPs with a threshold of $-\log _{10}$ ( $p$-value) $\geq 4$ were considered. Thus, 36 quantitative trait loci (QTLs), including 13 QTL clusters that were associated with more than one trait, were detected, and 31 QTLs were first identified. The QTL clusters on chromosomes $3 \mathrm{D}$ and $5 \mathrm{~B}$ were associated with four and five RSA traits, respectively. Two candidate genes, TraesCS2A01G516200 and TraesCS7B01G036900, were found to be associated with more than one RSA trait using haplotype analysis, and preferentially expressed in the root tissues. These favourable alleles for RSA traits identified in this study may be useful to optimise the root system in wheat.
\end{abstract}

Keywords: Triticum aestivum L.; root system architecture; genome-wide association study; quantitative trait loci; candidate genes

\section{Introduction}

Bread wheat (Triticum aestivum L.) is one of the most important staple crops worldwide. The cultivated area of wheat is approximately 217 million hectares, annually producing approximately 765 million tonnes [1]. However, the demand for wheat continues to increase owing to a rapid increase in population. According to the speculation by the Food and Agriculture Organisation of the United Nations, approximately 840 million tonnes of wheat will be required annually by 2050 [2]. However, wheat production is facing serious challenges with the increasing global climate change in recent years [3,4]. Wheat breeding for high yield and stress tolerance will remain the main strategy for a long time. Roots, the underground parts of plants, absorb nearly all of the nutrients required for plant development and are primarily exposed to osmotic stress [5]. Optimal RSA improves the wheat yield and stress tolerance [6,7]. Therefore, it is important to study the genetic mechanisms of crop RSA traits to optimise the root system for further breeding. 
RSA traits include root length, root surface area, root diameter, root tip number, and root volume [8]. RSA traits play important roles in determining crop development $[9,10]$, yield formation [11,12], and stress tolerance [13]. For marker-assisted selection and key gene identification, the QTLs for RSA traits were explored in different crops [14,15]. Zhang et al. [16] analysed the seminal root length in rice using a recombinant inbred line (RIL) population of 150 lines under different water supply conditions, and identified two QTLs that explained $10 \%$ and $11 \%$ of phenotypic variation. Li et al. [17] identified 46 environmentspecific QTLs for the crown root traits in maize, among which 12 QTLs were detected in multiple environments. Wu et al. [18] identified two major QTLs of swollen roots in turnips, providing a new idea regarding the molecular mechanism underlying storage root formation. In addition, Ren et al. [19] collated the QTLs for RSA and other traits, and found overlaps between QTLs for the root traits and those for nutrient uptake and productivity in many crop species, suggesting that RSA traits are closely related to crop development. These researches provided abundant information for further marker-assisted selection. Steele et al. [20] constructed introgressed lines using the previously reported root QTLs, which significantly improved the rice yield. Therefore, studying RSA traits is of great significance.

Bread wheat is consumed by $30-40 \%$ of humans [1]. Many researchers have paid attention to wheat root tissues. Manschadi et al. [10] analysed drought adaptation using wheat seedlings, and revealed that the root tissues are more closely related to drought tolerance than the aboveground tissues. Li et al. [21] found that deep roots, optimal root length density and xylem diameter, and increased root surface area contribute to drought tolerance. To elucidate the mechanisms of root development, many studies on QTL mapping of RSA traits have been performed in wheat. Liu et al. [22] analysed RSA traits using a diverse panel of 165 wheat cultivars, and identified 28 and 4 QTLs in hydroponic and field environments, respectively. Alemu et al. [23] analysed RSA traits using 192 Ethiopian durum wheat accessions, and identified 4 major $\left(-\log _{10} p \geq 4\right)$ and 34 nominal $\left(-\log _{10} p \geq 3.5\right)$ QTLs. Fan et al. [24] analysed the RSA traits in the seedlings of 188 RILs subjected to different nitrogen concentrations, and detected 53 QTLs responsible for RSA traits. In total, 26 published reports performed QTL exploration for RSA traits [5,19,22-45], which provided ample information on RSA traits in wheat.

The wheat genome is enormous and complex. Research on the quantitative traits in wheat lags behind the research on other crops [28]. Especially for the RSA traits, each trait is controlled by multiple genes. Although researchers identified many QTLs for RSA traits, a few genes were functionally verified to regulate root development using the forward genetic approaches in wheat $[46,47]$. The mechanism for the RSA traits remains unclear, and more loci need to be explored in wheat. For the completion of genome sequencing, many types of SNP chips were developed, and the 660K SNP chip was considered to be the optimal chip for GWAS in wheat [48]. In this study, a diversity panel of 388 wheat accessions, based on pre-diversity assessment, was used to analyse RSA traits at the seedling stage under two environments. The 660K SNP chip was used for GWAS. We expect to identify vital QTLs and candidate genes to improve RSA.

\section{Results}

\subsection{Population Structure and Linkage Disequilibrium (LD) Decay Analysis}

The population structure was determined using STRUCTURE V2.3.4 according to the $\Delta K$ method of Bayesian clustering. We determined the slope breakpoint at $K=8$. Thus, the panel used in this study was divided into eight subpopulations (Sp1-Sp8, Figure 1a, Table S1). Sp1 comprised 11 exotic varieties, 6 landraces, and 49 local cultivars. Sp2 consisted of 7 exotic varieties, 4 landraces, and 29 local cultivars. Sp3 comprised 5 exotic varieties, 1 landrace, and 58 local cultivars. Sp4 contained 13 exotic varieties, 15 landraces, and 19 local cultivars. Sp5 was composed of 10 exotic varieties, 3 landraces, and 28 local cultivars. Sp7 consisted of 1 exotic variety, 1 landrace, and 28 local cultivars. Sp8 contained 19 exotic varieties, 7 landraces, and 40 local cultivars (Table 1, Figure 1b). 

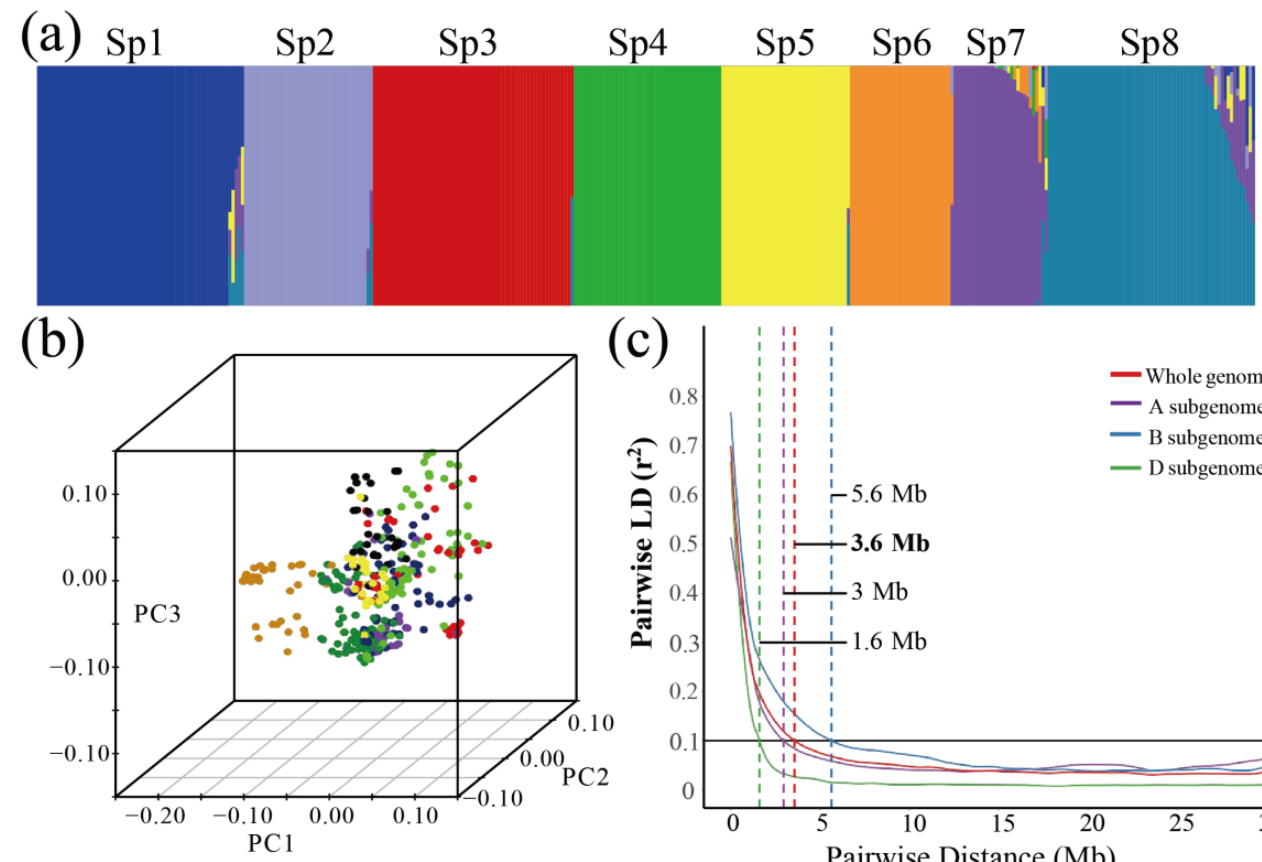

(b) (c)

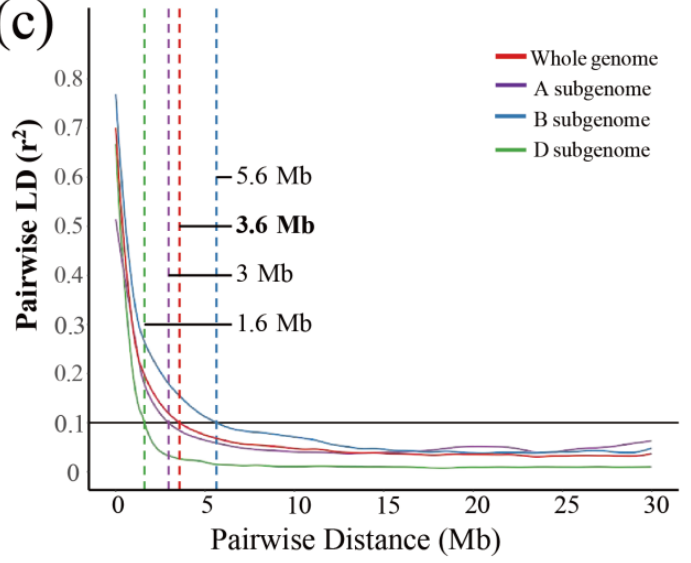

Figure 1. Population structure and LD analysis of the wheat panel. (a) Subpopulations inferred by Kmeans structure analysis. (b) Principal component analysis of all wheat accessions. (c) Genome-wide average LD decay over physical distance. Pair-wise single-nucleotide polyLD $\left(r^{2}\right)$ values based on the physical positions from the IWGSC RefSeq v.1.0 reference genome are plotted as a function of mapping distance $(\mathrm{Mb})$ between markers. The different-coloured curves represent LD decay fits for sub-genomes A (purple), B (blue), D (green), and the whole genome (red). The thick horizontal black line represents the population-specific critical $r^{2}$ value (0.1) above which LD may be due to linkage.

Table 1. Components of eight subpopulations.

\begin{tabular}{ccccc}
\hline Sub-Population & $\begin{array}{c}\text { Number of } \\
\text { Accession }\end{array}$ & Exotic Variety & Local Landrace & Local Cultivar \\
\hline Sp1 & 66 & 11 & 6 & 49 \\
Sp2 & 41 & 7 & 5 & 29 \\
Sp3 & 64 & 5 & 1 & 58 \\
Sp4 & 47 & 13 & 15 & 19 \\
Sp5 & 41 & 0 & 3 & 28 \\
Sp6 & 33 & 1 & 0 & 33 \\
Sp7 & 30 & 19 & 7 & 28 \\
Sp8 & 66 & & 70 \\
\hline
\end{tabular}

We estimated the degree of LD using 161,801, 184,658, and 58,479 SNP markers in the A, B, and D sub-genomes, respectively. LD was analysed based on 717,701,068 pairwise comparisons of 404,938 SNPs. Pair-wise LD was estimated using the squared allelefrequency correlation $\left(r^{2}\right)$. A plot of the LD estimates $\left(r^{2}\right)$ as a function of physical distance $(\mathrm{Mb})$ indicated clear LD decay with increasing physical distance (Figure 1c). A comparison of LD between the sub-genomes and chromosomes showed variances in the LD decay. Overall, the average LD decay distance in the whole genome was approximately 3.6 Mb. LD decayed faster in the $\mathrm{D}$ genome $(1.6 \mathrm{Mb})$ than in the $\mathrm{A}(3 \mathrm{Mb})$ and $\mathrm{B}(5.6 \mathrm{Mb})$ genomes (Figure 1c). The faster LD decay in the D genome is compatible with the evolutionary history of wheat. 


\subsection{Phenotypic Variation of the RSA Traits}

A total of 4656 (388 wheat accessions $\times 6$ replications $\times 2$ environments) seedling roots were collected and observed for the nine RSA traits namely, total root length (TRL), total root surface area (TRA), average root diameter (ARD), total root volume (TRV), number of root tips (NRT), root length (RL), root surface area (RA), root volume (RV), and root tips (RT) (Table S1). The frequency distribution of the investigated traits was normal, as indicated by the kurtosis (bk) and skewness (bs) (Figure 2). This means that the traits were quantitative and suitable for GWAS. Phenotypic variation analysis showed that the nine RSA traits exhibited greater variation under OPC than under IPC, indicated by the coefficient of variation (Table 2). In addition, the nine RSA traits were significantly higher under OPC than under IPC ( $p \leq 0.001)$. In other words, the root development was faster under OPC than that under IPC. The broad-sense heritability $\left(\mathrm{H}^{2}\right)$ of the nine RSA traits ranged from $66.78 \%$ to $77.83 \%$, indicating that the variations observed in these RSA traits were mainly regulated by genotype.
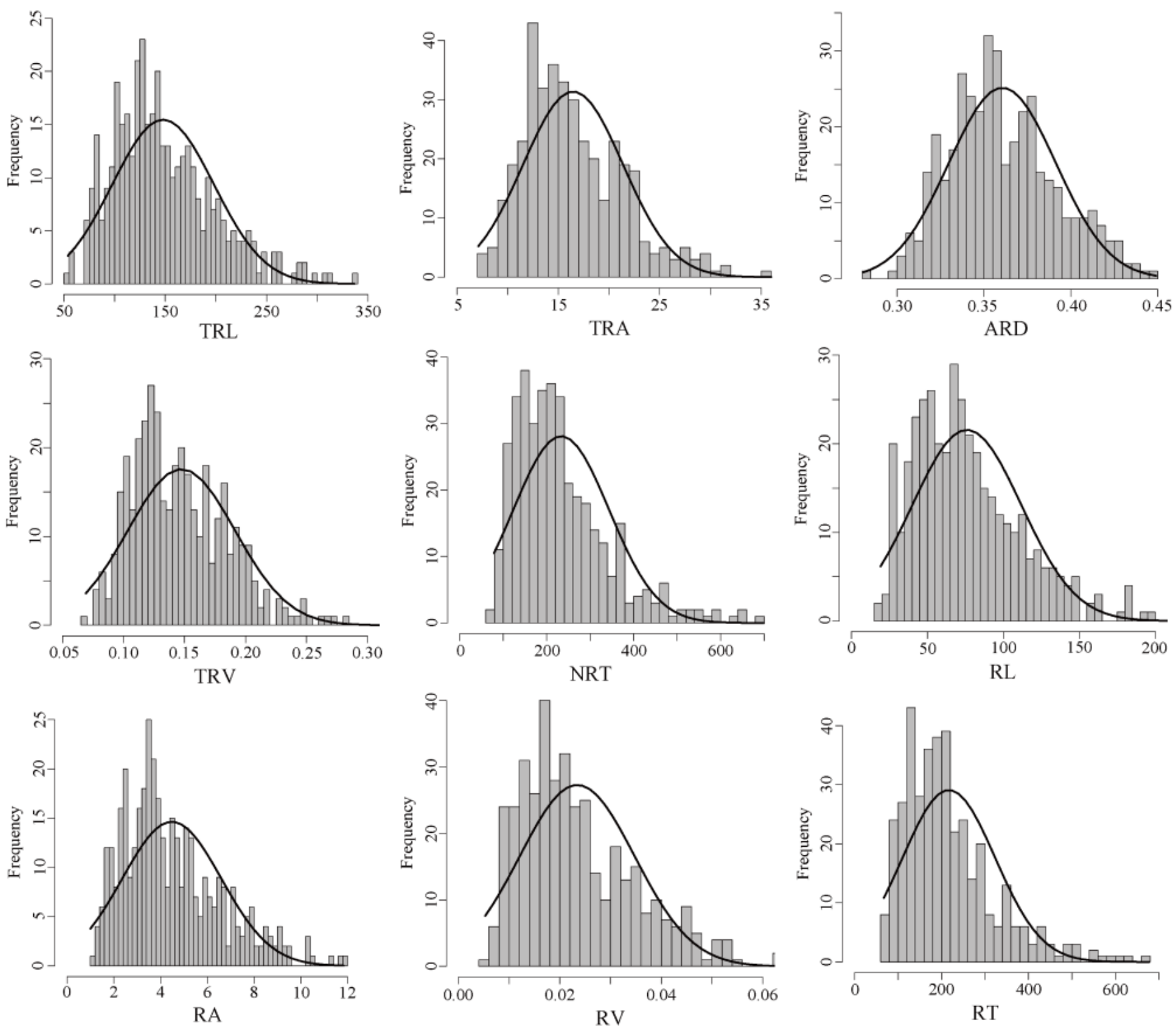

Figure 2. Distribution frequency of the RSA traits of 388 wheat accessions under OPC. The black curve represents the density curve. 
Table 2. Phenotypic analysis of nine RSA traits for this wheat panel under two environments.

\begin{tabular}{|c|c|c|c|c|c|c|c|c|c|c|c|}
\hline Trait & $\mathbf{E}$ & Mean & SD & Min & Max & bk & bs & CV (\%) & $H^{2}(\%)$ & $p$-Value & $<0.001$ \\
\hline \multirow{2}{*}{ TRL } & $\mathrm{OPC}$ & 236.06 & 94.96 & 64.25 & 645.14 & 1.84 & 1.14 & $40.22 \%$ & $77.83 \%$ & $7.96175 \times 10^{-51}$ & $* * *$ \\
\hline & IPC & 147.91 & 50.03 & 53.91 & 336.76 & 0.65 & 0.83 & $33.82 \%$ & & & \\
\hline \multirow{2}{*}{ TRA } & OPC & 31.68 & 12.98 & 9.50 & 86.52 & 1.25 & 0.91 & $40.97 \%$ & $76.86 \%$ & $2.91719 \times 10^{-81}$ & $* * *$ \\
\hline & IPC & 16.45 & 4.93 & 7.11 & 36.00 & 0.55 & 0.80 & $29.94 \%$ & & & \\
\hline \multirow[b]{2}{*}{ ARD } & OPC & 0.43 & 0.07 & 0.27 & 0.58 & -1.06 & -0.32 & $16.91 \%$ & $66.78 \%$ & $9.8363 \times 10^{-58}$ & $* * *$ \\
\hline & IPC & 0.36 & 0.03 & 0.28 & 0.45 & -0.29 & 0.37 & $8.52 \%$ & & & \\
\hline \multirow{2}{*}{ TRV } & OPC & 0.35 & 0.17 & 0.07 & 1.09 & 1.51 & 0.95 & $47.94 \%$ & $76.86 \%$ & $4.92408 \times 10^{-89}$ & $* * *$ \\
\hline & IPC & 0.15 & 0.04 & 0.07 & 0.44 & 6.18 & 1.60 & $29.81 \%$ & & & \\
\hline \multirow{2}{*}{ NRT } & $\mathrm{OPC}$ & 360.80 & 186.97 & 113.00 & 1703.67 & 8.55 & 2.20 & $51.82 \%$ & $72.38 \%$ & $1.24864 \times 10^{-28}$ & $* * *$ \\
\hline & IPC & 233.30 & 110.08 & 78.67 & 699.83 & 2.14 & 1.36 & $47.18 \%$ & & & \\
\hline \multirow{2}{*}{ RL } & OPC & 113.91 & 63.29 & 18.27 & 429.16 & 4.95 & 1.83 & $55.56 \%$ & $75.71 \%$ & $3.14966 \times 10^{-23}$ & $* * *$ \\
\hline & IPC & 75.99 & 35.82 & 19.24 & 225.26 & 1.06 & 0.98 & $47.14 \%$ & & & \\
\hline \multirow{2}{*}{ RA } & OPC & 6.90 & 3.59 & 1.15 & 24.26 & 3.78 & 1.62 & $52.08 \%$ & $76.15 \%$ & $6.77309 \times 10^{-28}$ & $* * *$ \\
\hline & IPC & 4.48 & 2.11 & 1.01 & 11.82 & 0.44 & 0.89 & $47.13 \%$ & & & \\
\hline \multirow{2}{*}{ RV } & OPC & 0.04 & 0.02 & 0.0067 & 0.1214 & 3.04 & 1.49 & $50.12 \%$ & $76.06 \%$ & $7.24198 \times 10^{-31}$ & $* * *$ \\
\hline & IPC & 0.02 & 0.01 & 0.0053 & 0.0626 & 0.25 & 0.87 & $48.38 \%$ & & & \\
\hline \multirow{2}{*}{ RT } & OPC & 311.12 & 187.64 & 45.33 & 1641.83 & 8.30 & 2.20 & $60.31 \%$ & $71.15 \%$ & $4.80007 \times 10^{-17}$ & $* * *$ \\
\hline & IPC & 216.96 & 106.31 & 67.33 & 678.00 & 2.22 & 1.36 & $49.00 \%$ & & & \\
\hline
\end{tabular}

E, Environments; bk, kurtosis; bs, skewness; $\mathrm{CV}$, coefficient of variation; $H^{2}$, heritability; ${ }^{* * *}$ Significant at $p \leq 0.001$.

\subsection{Correlations between RSA Traits}

The relationships of the nine RSA traits between the two environments were analysed. The results showed that each RSA trait showed a significant correlation $(p \leq 0.001)$ between the two environments. This means that these traits were mainly regulated by genotype. The relationships between the nine traits were calculated (Figure 3). The results showed that significant positive correlations were observed between eight RSA traits, except for ARD. ARD showed a significant negative correlation with NRT, RL, RA, RV, and RT in the two environments. The correlation coefficients between RL, RA, and RV were higher than 0.94 in the two environments, indicating that these three traits were strongly correlated.

(a)

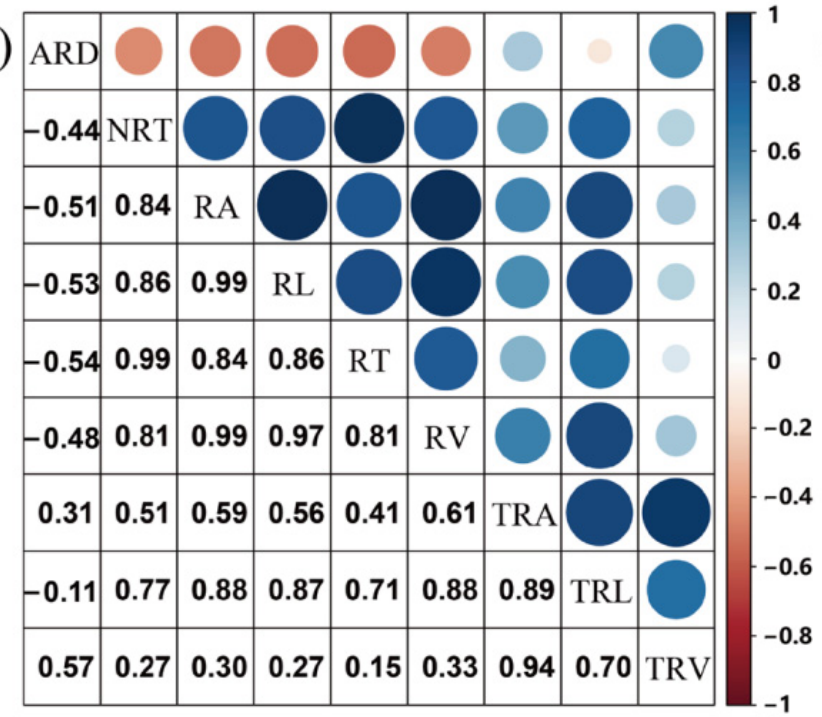

(b)

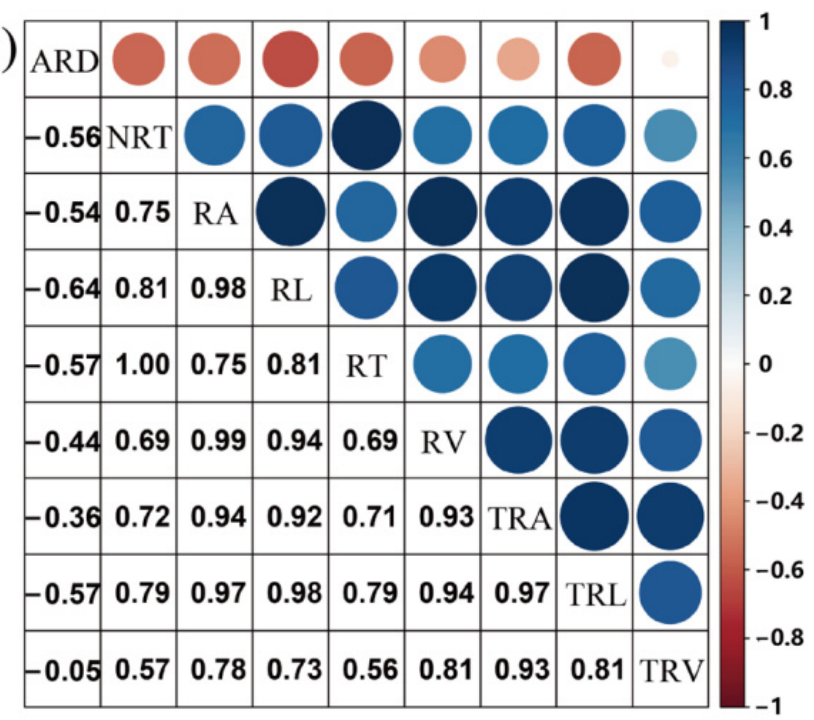

Figure 3. Correlation analysis of the nine RSA traits in 388 wheat accessions under OPC (a) and IPC (b). Intensities of the blue and red colours indicate the degree of positive and negative correlations, respectively. Circle size indicates low to high significance. 


\subsection{GWAS of RSA Traits}

After filtering low-quality SNPs (minor allele frequency $<0.05$ and missing data $>0.1$ ), a total of 411,605 polymorphic SNP markers with effective chromosome information were available for GWAS using a univariate mixed linear model of GEMMA (Table S2). Of these, 404,938 SNPs were mapped to 21 wheat chromosomes, with 161,801, 184,658, and 58,479 SNPs in the A, B, and D sub-genomes, respectively. The marker density varied among different chromosomes (Figure S1, Table 3). We discovered that the minimum marker density was 8.1 markers per $\mathrm{Mb}$ on chromosome $4 \mathrm{D}$, whereas the maximum was 55.09 markers per $\mathrm{Mb}$ on chromosome 3B. Compared with the A and B sub-genomes, the $\mathrm{D}$ sub-genome had fewer SNP markers and effective markers, especially chromosome 4D, which contained 1702 SNPs. The markers of known chromosome positions were used to analyse the genetic diversity. We found that there was little difference in the genetic diversity among the three sub-genomes. The mean values of the expected heterozygosity $(\mathrm{He})$ and polymorphism information content (PIC) were $0.66-0.74$ and $0.27-0.30$ among the three sub-genomes, respectively.

We performed a GWAS using the best linear unbiased predictions (BLUPs) of the nine RSA traits. Significant SNPs for each trait were selected with a threshold of $-\log _{10}$ ( $p$-value) $\geq 3.5$ (Table S3, Figure S2). After analysing the data, 133 QTLs evenly distributed on 21 chromosomes were identified for the nine RSA traits, among which 38 were associated with multiple RSA traits. Eight QTLs were overlapped with previously identified QTLs (Table S3).

We focused on significant SNPs with a threshold of $-\log _{10}$ ( $p$-value) $\geq 4$. For convenience, we selected tagged SNPs for each QTL exhibiting the strongest association with RSA traits (Table 4), yielding 36 QTLs on 17 chromosomes (Figure 4), of which 13 were associated with more than one RSA trait. Among these QTLs, five QTLs, mapped on chromosomes 5B, 6B, 6D, 7A, and 7B, were co-localised with those identified in previous studies (Table 4), indicating that our results were reliable. 
Table 3. Summary of the genetic diversity in three sub-genomes and chromosomes of this wheat panel and evaluation of the effective number of independent SNPs, including the suggested $p$ value thresholds.

\begin{tabular}{|c|c|c|c|c|c|c|c|c|c|}
\hline Chromosome & $\begin{array}{c}\text { No. of } \\
\text { Markers }\end{array}$ & $\begin{array}{l}\text { Effective } \\
\text { Number }\end{array}$ & $\begin{array}{c}\text { Effective } \\
\text { Ratio }\end{array}$ & $\begin{array}{l}\text { Suggested } \\
p \text {-Value }\end{array}$ & $\begin{array}{c}\% \\
\text { Markers }\end{array}$ & $\begin{array}{c}\text { Length } \\
\text { (Mb) }\end{array}$ & $\begin{array}{l}\text { Marker } \\
\text { Density }\end{array}$ & $\mathrm{He}$ & PIC \\
\hline $1 \mathrm{~A}$ & 28793 & 5643.19 & 0.20 & $1.77 \times 10^{-4}$ & 7.00 & 594.02 & 48.47 & 0.65 & 0.26 \\
\hline $2 \mathrm{~A}$ & 28676 & 6088.17 & 0.21 & $1.64 \times 10^{-4}$ & 6.97 & 780.76 & 36.73 & 0.71 & 0.28 \\
\hline $3 \mathrm{~A}$ & 19366 & 4607.43 & 0.24 & $2.17 \times 10^{-4}$ & 4.70 & 750.73 & 25.80 & 0.68 & 0.28 \\
\hline $4 \mathrm{~A}$ & 17856 & 4241.96 & 0.24 & $2.36 \times 10^{-4}$ & 4.34 & 744.54 & 23.98 & 0.66 & 0.27 \\
\hline $5 \mathrm{~A}$ & 22482 & 4935.88 & 0.22 & $2.03 \times 10^{-4}$ & 5.46 & 709.76 & 31.68 & 0.78 & 0.31 \\
\hline $6 \mathrm{~A}$ & 16438 & 3851.64 & 0.23 & $2.60 \times 10^{-4}$ & 3.99 & 617.97 & 26.60 & 0.73 & 0.29 \\
\hline $7 \mathrm{~A}$ & 28190 & 6297.36 & 0.22 & $1.59 \times 10^{-4}$ & 6.85 & 736.69 & 38.27 & 0.68 & 0.27 \\
\hline $1 \mathrm{~B}$ & 20584 & 4750.1 & 0.23 & $2.11 \times 10^{-4}$ & 5.00 & 689.38 & 29.86 & 0.75 & 0.30 \\
\hline $2 \mathrm{~B}$ & 28715 & 6701.21 & 0.23 & $1.49 \times 10^{-4}$ & 6.98 & 801.25 & 35.84 & 0.73 & 0.29 \\
\hline 3B & 45766 & 7920.52 & 0.17 & $1.26 \times 10^{-4}$ & 11.12 & 830.70 & 55.09 & 0.78 & 0.31 \\
\hline $4 B$ & 13130 & 3016.41 & 0.23 & $3.32 \times 10^{-4}$ & 3.19 & 673.47 & 19.50 & 0.72 & 0.29 \\
\hline $5 B$ & 33874 & 6596.79 & 0.19 & $1.52 \times 10^{-4}$ & 8.23 & 713.02 & 47.51 & 0.79 & 0.31 \\
\hline $6 \mathrm{~B}$ & 25549 & 5554.71 & 0.22 & $1.80 \times 10^{-4}$ & 6.21 & 720.95 & 35.44 & 0.69 & 0.28 \\
\hline $7 \mathrm{~B}$ & 17040 & 4491.9 & 0.26 & $2.23 \times 10^{-4}$ & 4.14 & 750.61 & 22.70 & 0.72 & 0.29 \\
\hline $1 \mathrm{D}$ & 10597 & 3058.85 & 0.29 & $3.27 \times 10^{-4}$ & 2.57 & 495.44 & 21.39 & 0.68 & 0.28 \\
\hline $2 \mathrm{D}$ & 10430 & 3731.57 & 0.36 & $2.68 \times 10^{-4}$ & 2.53 & 651.81 & 16.00 & 0.69 & 0.28 \\
\hline $3 \mathrm{D}$ & 7291 & 2668.7 & 0.37 & $3.75 \times 10^{-4}$ & 1.77 & 615.48 & 11.85 & 0.67 & 0.27 \\
\hline $4 \mathrm{D}$ & 4128 & 1702.71 & 0.41 & $5.87 \times 10^{-4}$ & 1.00 & 509.85 & 8.10 & 0.66 & 0.27 \\
\hline $5 \mathrm{D}$ & 8437 & 3285.78 & 0.39 & $3.04 \times 10^{-4}$ & 2.05 & 566.04 & 14.91 & 0.65 & 0.26 \\
\hline $6 \mathrm{D}$ & 7486 & 2940.59 & 0.39 & $3.40 \times 10^{-4}$ & 1.82 & 473.56 & 15.81 & 0.64 & 0.26 \\
\hline 7D & 10110 & 3669.4 & 0.36 & $2.73 \times 10^{-4}$ & 2.46 & 638.65 & 15.83 & 0.64 & 0.26 \\
\hline A genome & 161801 & & & & 39.31 & 4934.47 & 32.79 & 0.70 & 0.28 \\
\hline$B$ genome & 184658 & & & & 44.86 & 5719.38 & 32.29 & 0.74 & 0.30 \\
\hline D genome & 58479 & & & & 14.21 & 3950.83 & 14.80 & 0.66 & 0.27 \\
\hline Total & 404938 & 95754.87 & & & & $14,064.68$ & 28.79 & 0.70 & 0.28 \\
\hline Average & & & & $2.51 \times 10^{-4}$ & & & & & \\
\hline
\end{tabular}


Table 4. QTLs and QTL clusters with RSA traits and overlapping with QTLs from previous studies.

\begin{tabular}{|c|c|c|c|c|c|c|c|}
\hline Traits & SNP & CHR & $\mathbf{M b}$ & $p$ & $-\log _{10}(p)$ & $R^{2}(\%)$ & Reference \\
\hline ARD & AX-94798162 & $2 B$ & 245.89 & $8.53 \times 10^{-5}$ & 4.07 & 1.23 & \\
\hline ARD & AX-94757865 & $2 \mathrm{~B}$ & 797.54 & $6.71 \times 10^{-5}$ & $4.17-4.38$ & $2.24-2.76$ & \\
\hline ARD & AX-110887844 & $2 \mathrm{D}$ & 380.98 & $7.38 \times 10^{-5}$ & 4.13 & 2.57 & \\
\hline ARD & AX-109125375 & $2 \mathrm{D}$ & 640.04 & $9.95 \times 10^{-5}$ & $4.00-5.38$ & $1.82-3.41$ & \\
\hline TRV & AX-108892435 & $3 \mathrm{~A}$ & 21.28 & $7.86 \times 10^{-5}$ & 4.10 & 2.58 & \\
\hline ARD & AX-111490934 & $3 B$ & 49.29 & $9.67 \times 10^{-5}$ & 4.01 & 3.59 & \\
\hline TRV & AX-94897906 & $4 \mathrm{~A}$ & 102.39 & $9.21 \times 10^{-5}$ & 4.04 & 2.28 & \\
\hline TRV & AX-110712645 & $4 \mathrm{~B}$ & 606.85 & $7.29 \times 10^{-5}$ & $4.14-4.74$ & $4.77-5.11$ & \\
\hline TRV & AX-95073736 & $5 \mathrm{~A}$ & 632.60 & $5.59 \times 10^{-5}$ & 4.25 & 2.64 & \\
\hline TRL & AX-111537095 & $5 B$ & 639.68 & $9.81 \times 10^{-5}$ & $4.01-4.30$ & $4.16-4.95$ & \\
\hline ARD & AX-95093123 & $5 \mathrm{D}$ & 385.39 & $2.69 \times 10^{-5}$ & 4.57 & 2.31 & \\
\hline ARD & AX-94999582 & $6 \mathrm{~A}$ & 104.36 & $6.99 \times 10^{-5}$ & 4.16 & 4.23 & \\
\hline ARD & AX-94827303 & $6 \mathrm{~A}$ & 115.18 & $8.43 \times 10^{-5}$ & 4.07 & 2.84 & \\
\hline ARD & AX-94502864 & $6 \mathrm{~B}$ & 710.32 & $7.22 \times 10^{-6}$ & 5.14 & 3.17 & [27] \\
\hline ARD & AX-94826824 & $6 \mathrm{D}$ & 60.14 & $5.84 \times 10^{-5}$ & 4.23 & 2.36 & \\
\hline ARD & AX-94468039 & $6 \mathrm{D}$ & 86.37 & $7.64 \times 10^{-5}$ & 4.12 & 3.18 & \\
\hline ARD & AX-110837768 & $6 \mathrm{D}$ & 464.84 & $6.32 \times 10^{-5}$ & 4.20 & 2.29 & [28] \\
\hline ARD & AX-94849869 & $7 \mathrm{~A}$ & 19.01 & $7.99 \times 10^{-5}$ & 4.10 & 3.46 & \\
\hline RT & AX-108852993 & $7 \mathrm{~A}$ & 40.26 & $7.97 \times 10^{-5}$ & 4.10 & 3.76 & \\
\hline NRT & AX-94970901 & $7 \mathrm{~A}$ & 692.05 & $8.53 \times 10^{-5}$ & 4.07 & 4.03 & [27] \\
\hline RT & AX-95181992 & $7 \mathrm{~B}$ & 228.81 & $5.95 \times 10^{-5}$ & 4.23 & 3.84 & \\
\hline ARD & AX-109581543 & $7 \mathrm{~B}$ & 403.54 & $3.66 \times 10^{-5}$ & 4.44 & 3.03 & [29] \\
\hline ARD & AX-110360435 & $7 \mathrm{D}$ & 104.09 & $9.83 \times 10^{-5}$ & 4.01 & 2.24 & \\
\hline TRA/TRV & AX-111630548 & $2 \mathrm{~A}$ & 61.28 & $8.82 \times 10^{-5}$ & $4.05-4.29$ & $2.68-3.20$ & \\
\hline TRA/TRV & AX-110564036 & $2 \mathrm{~A}$ & 740.01 & $8.78 \times 10^{-5}$ & $4.06-4.11$ & $3.41-3.69$ & \\
\hline TRA/TRV & AX-109537244 & $2 B$ & 694.26 & $8.70 \times 10^{-5}$ & $4.06-4.29$ & $2.52-2.64$ & \\
\hline NRT/RT & AX-95193648 & $3 \mathrm{~A}$ & 0.56 & $2.39 \times 10^{-5}$ & $4.62-4.92$ & $3.97-4.29$ & \\
\hline NRT/RT & AX-94711043 & $3 B$ & 0.99 & $1.17 \times 10^{-5}$ & $4.93-5.14$ & $4.28-4.42$ & \\
\hline NRT/RT & AX-109337192 & $3 B$ & 2.28 & $3.94 \times 10^{-5}$ & $4.40-4.80$ & $3.77-4.16$ & \\
\hline TRL/RL/RA/RV & AX-109237510 & $3 \mathrm{D}$ & 549.74 & $9.90 \times 10^{-5}$ & $4.00-4.16$ & $3.68-4.58$ & \\
\hline NRT $/ \mathrm{RT}$ & AX-110444857 & $4 \mathrm{~A}$ & 584.71 & $9.92 \times 10^{-5}$ & $4.00-4.37$ & $4.64-4.78$ & \\
\hline NRT/RT/RL/RA/RV & AX-86179446 & $5 \mathrm{~B}$ & 571.23 & $9.98 \times 10^{-5}$ & $4.00-5.73$ & $3.99-6.77$ & [28] \\
\hline NRT $/$ RT & AX-110522657 & $5 \mathrm{D}$ & 464.07 & $8.90 \times 10^{-5}$ & $4.05-4.66$ & $3.97-5.60$ & \\
\hline NRT/RT & AX-111060833 & $6 \mathrm{~B}$ & 127.23 & $5.66 \times 10^{-5}$ & $4.25-4.42$ & $4.00-4.15$ & \\
\hline TRL/TRA & AX-95155829 & $7 \mathrm{~B}$ & 36.49 & $4.72 \times 10^{-5}$ & $4.33-4.58$ & $4.51-4.80$ & \\
\hline TRL/TRA & AX-94759416 & $7 \mathrm{~B}$ & 594.41 & $8.96 \times 10^{-5}$ & $4.05-4.23$ & $4.00-5.28$ & \\
\hline
\end{tabular}



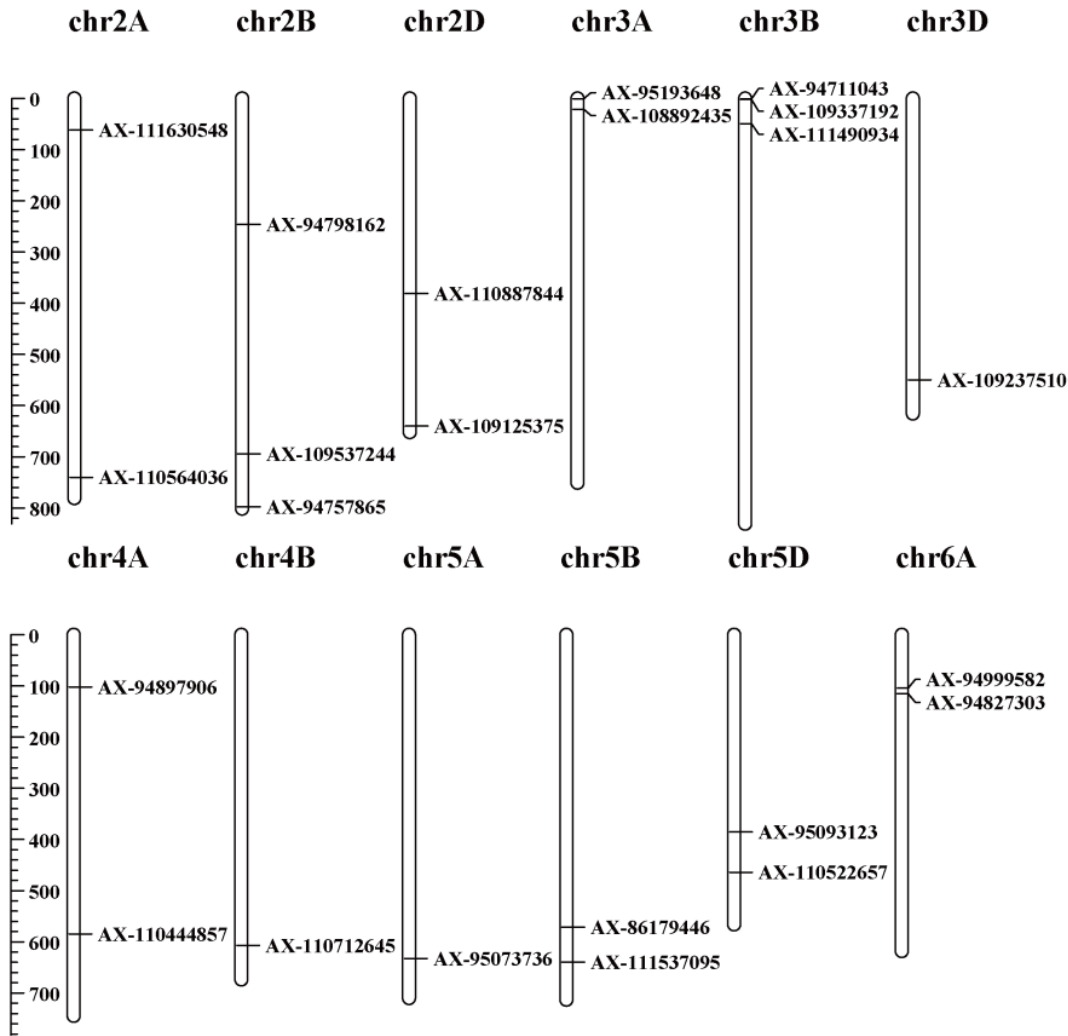

chr6B chr6D chr7A chr7B chr7D

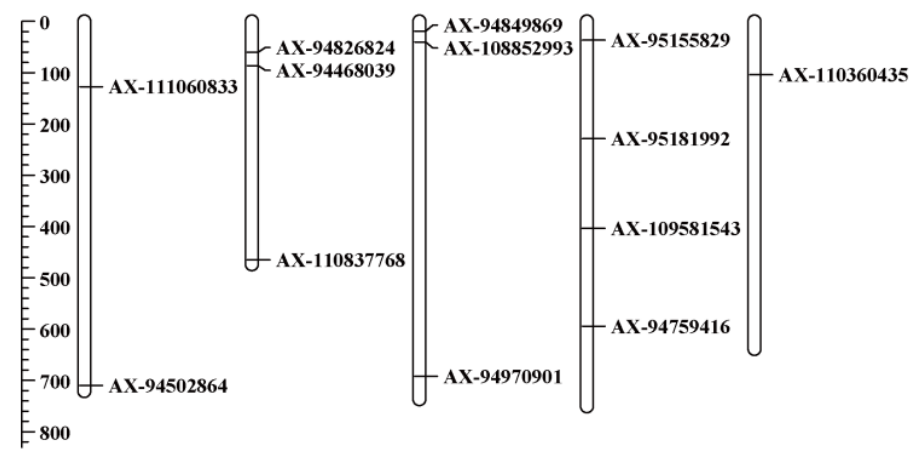

Figure 4. Location of the QTLs for the RSA traits (- $\log _{10}[p$-value $\left.] \geq 4\right)$.

\subsection{QTL Clusters for Root System Architecture Traits}

QTL clusters refer to the QTLs that were associated with more than one RSA trait. We identified 13 QTL clusters located on chromosomes 2A, 2B, 3A, 3B, 3D, 4A, 5B, 5D, 6B, and 7B. Chromosomes 2A, 3B, and 7B contained two QTL clusters, and chromosomes 2B, 3A, 3D, 4A, 5B, 5D, and 6B harboured a single QTL cluster. One QTL cluster on chromosome 5B $(571.23 \mathrm{Mb})$ was associated with five RSA traits: RL, RA, RV, RT, and NRT. One QTL cluster on chromosome 3D (549.74 Mb) was associated with four RSA traits: RL, RA, RV, and TRL. Two QTL clusters on chromosome $2 \mathrm{~A}(61.28 \mathrm{Mb}$ and $740.01 \mathrm{Mb})$ and one QTL cluster on chromosome 2B (694.26 Mb) were associated with TRA and TRV. Two QTL clusters on chromosome 7B were associated with TRL and TRA. One QTL cluster on chromosome $3 \mathrm{~A}$, two on chromosome $3 \mathrm{~B}$, one on chromosome $4 \mathrm{~A}$, one on chromosome $5 \mathrm{D}$, and one on chromosome 6B were associated with RT and NRT. Therefore, these QTL clusters showed a pleiotropic effect. 


\subsection{Candidate Genes Associated with RSA}

A total of 649 genes were identified in the 13 QTL clusters (Table S4). The genes encoding the bHLH transcription factor, WUSCHEL-RELATED HOMEOBOX 4 (WOX4), ROOT HAIR DEFECTIVE 6 (RHD6), GLABRA 3 (GL3), and ROOTHAIRLESS-LIKE 1 (LRL1), which are closely related to RSA traits, were found in the QTL clusters. We analysed the significant SNPs in thirteen QTL clusters, and identified nine genes with nonsynonymous polymorphisms across the wheat panel (Table S5). The phenotypic variation related to each haplotype of the above nine genes was characterised, and the phenotypic differences between the haplotypes of two genes, TraesCS2A01G516200 with the SNP AX110564036 (GG/AA) and TraesCS7B01G036900 with the SNP AX-112287343 (CC/TT), were significant $(p \leq 0.05)$ in more than one RSA trait.

TraesCS2A01G516200 (AX-110564036), mapped to chromosome 2A between $739.8 \mathrm{Mb}$ and $740.8 \mathrm{Mb}$, encoded a short-chain dehydrogenase/reductase (Figure 5a). AX-110564036 SNP caused an amino acid change from isoleucine (Ile) to valine (Val) at $167 \mathrm{bp}$ in this gene (Figure 5b). The 388 accessions were divided into two haplotypes (GG or AA) according to their genotype at this SNP. We determined that 258 and 93 accessions harboured the GG and AA haplotypes, respectively, whereas the remaining 37 accessions were heterozygous or lacked genotype information. Under the two environments, the accessions carrying the AA allele showed significantly higher values of the RSA traits TRL, TRA, and NRT than those carrying the GG allele ( $p \leq 0.05)$, indicating that the AA haplotype had a positive effect on RSA (Figure 5c). RT-qPCR analysis showed that this gene was preferentially expressed in the root tissues at the jointing and heading stages (Figure 5d). These results showed that TraesCS2A01G516200 plays an important role in the RSA traits of wheat.

TraesCS7B01G036900 (AX-112287343), mapped to chromosome 7B between $35 \mathrm{Mb}$ and $36 \mathrm{Mb}$, encoded a development and cell death domain protein (Figure 6a). AX-112287343 SNP caused an amino acid change from valine (Val) to alanine (Ala) at $396 \mathrm{bp}$ in this gene (Figure 6b). The 388 accessions were divided into two haplotypes (CC or TT) according to their genotype at this SNP. We determined that 348 and 36 accessions harboured the CC and TT haplotypes, respectively, while the remaining four accessions were heterozygous or lacked genotype information. Under the two environments, the accessions with the CC haplotype exhibited markedly higher RSA trait values for TRL, TRA, TRV, RL, RA, and RV than those with the TT haplotype $(p \leq 0.05)$, indicating that the CC haplotype had a positive effect on RSA (Figure 6c). The RT-qPCR analysis indicated that this gene was preferentially expressed in the root tissues at the jointing and heading stages (Figure 6d). These results showed that TraesCS7B01G036900 plays an important role in the RSA traits of wheat. 
(a)

(b)
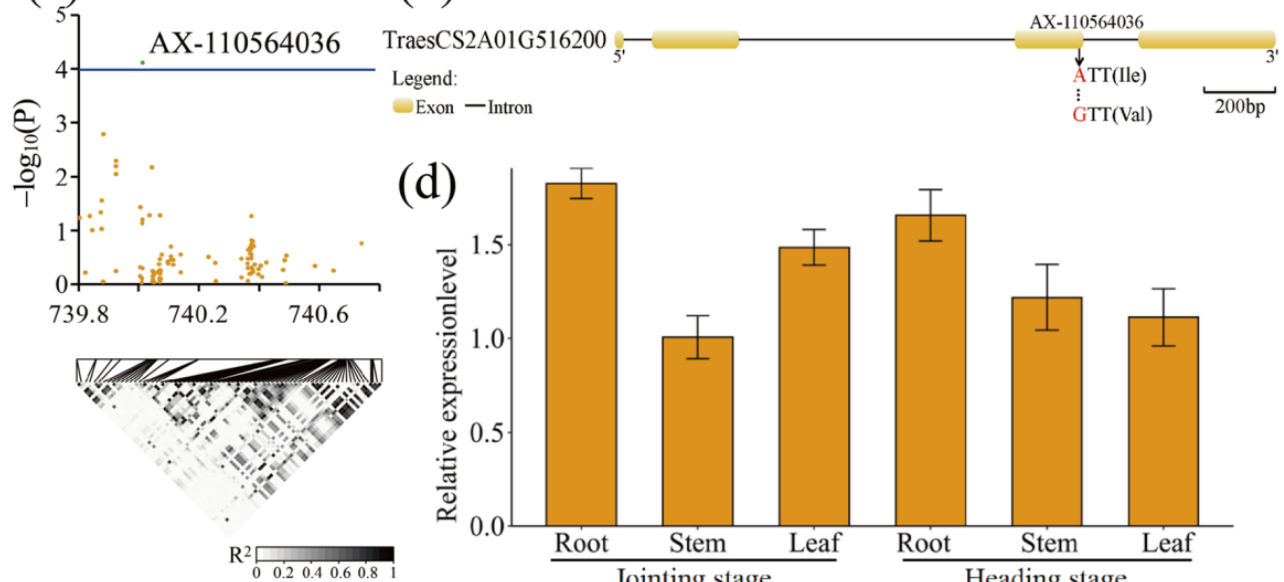

(d)
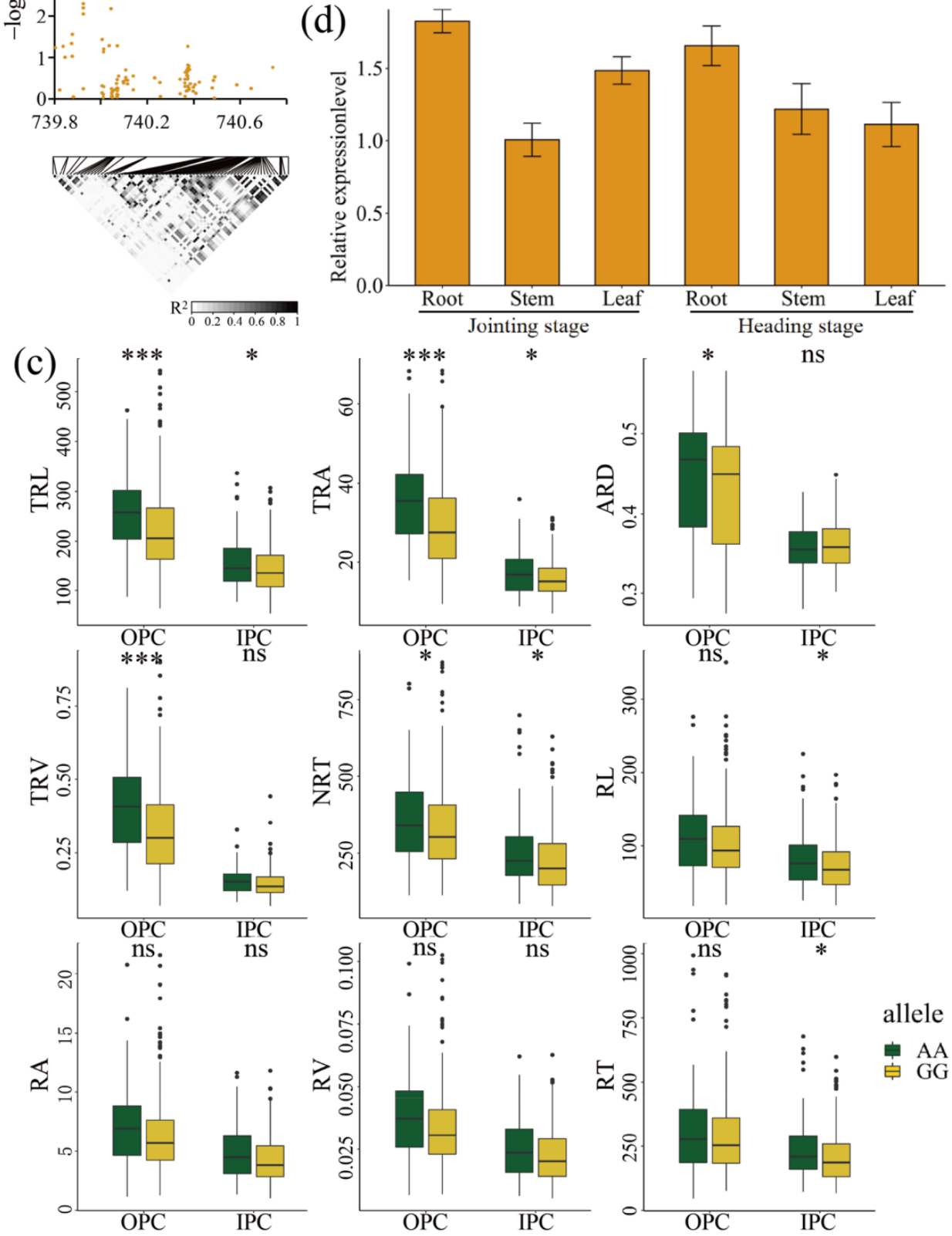

Figure 5. GWAS results of the nine RSA traits and identification of candidate gene for the SNP AX-110564036 on chromosome 2A. (a) Manhattan plot for the candidate region on chromosome 2A. The green dot represents the significant SNP AX-110564036. The LD block analysis of the SNPs in this region is shown below. The degree of linkage is represented by the coefficient of $r^{2}$. (b) Gene structure of TraesCS2A01G516200 and its non-synonymous SNP. Yellow rectangles and black lines represent exons and introns, respectively. The arrow indicates the position of amino acid variations in TraesCS2A01G516200. (c) Box plots for RSA traits based on the allele at SNP AX-110564036. Differences between the haplotypes were statistically analysed using the Student's $t$-test. The upper and lower edges of the box represent the 75th and 25th quantiles, respectively, and the whiskers show the 90th and 10th quantiles; the horizontal solid line represents the average; * Significant at $p \leq 0.05$, ** Significant at $p \leq 0.001$. (d) Expression profile of TraesCS2A01G516200 in different tissues, as determined by RT-qPCR. The data are the means \pm Sd of $n=3$. 'ns' means 'not significant'. 
(a)

(b)
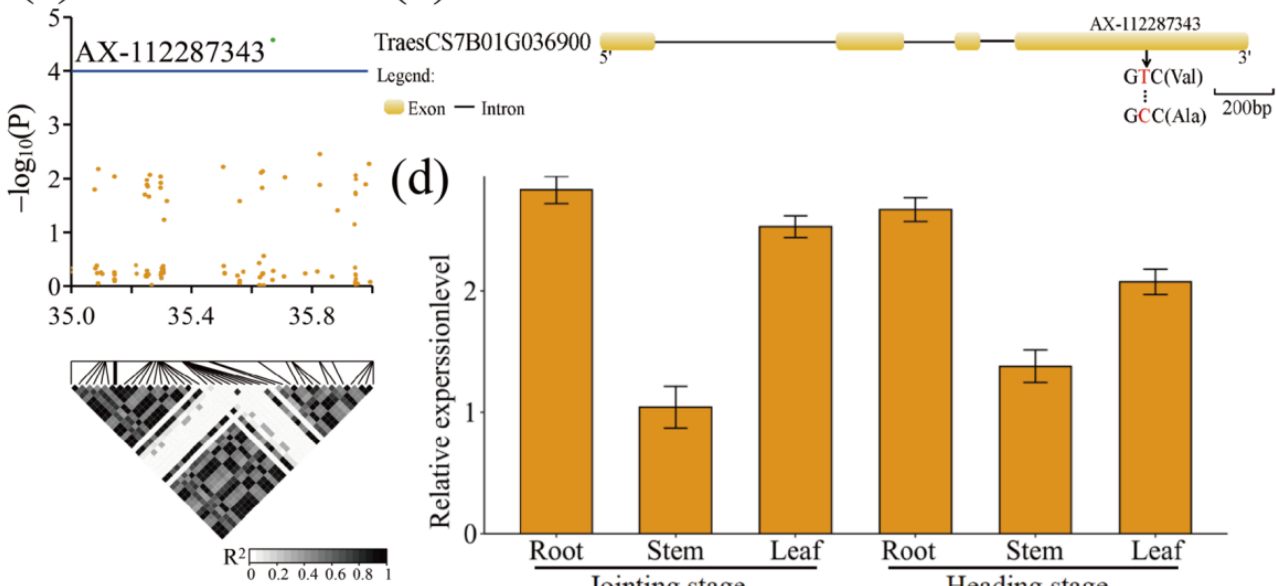

(c)

(d)
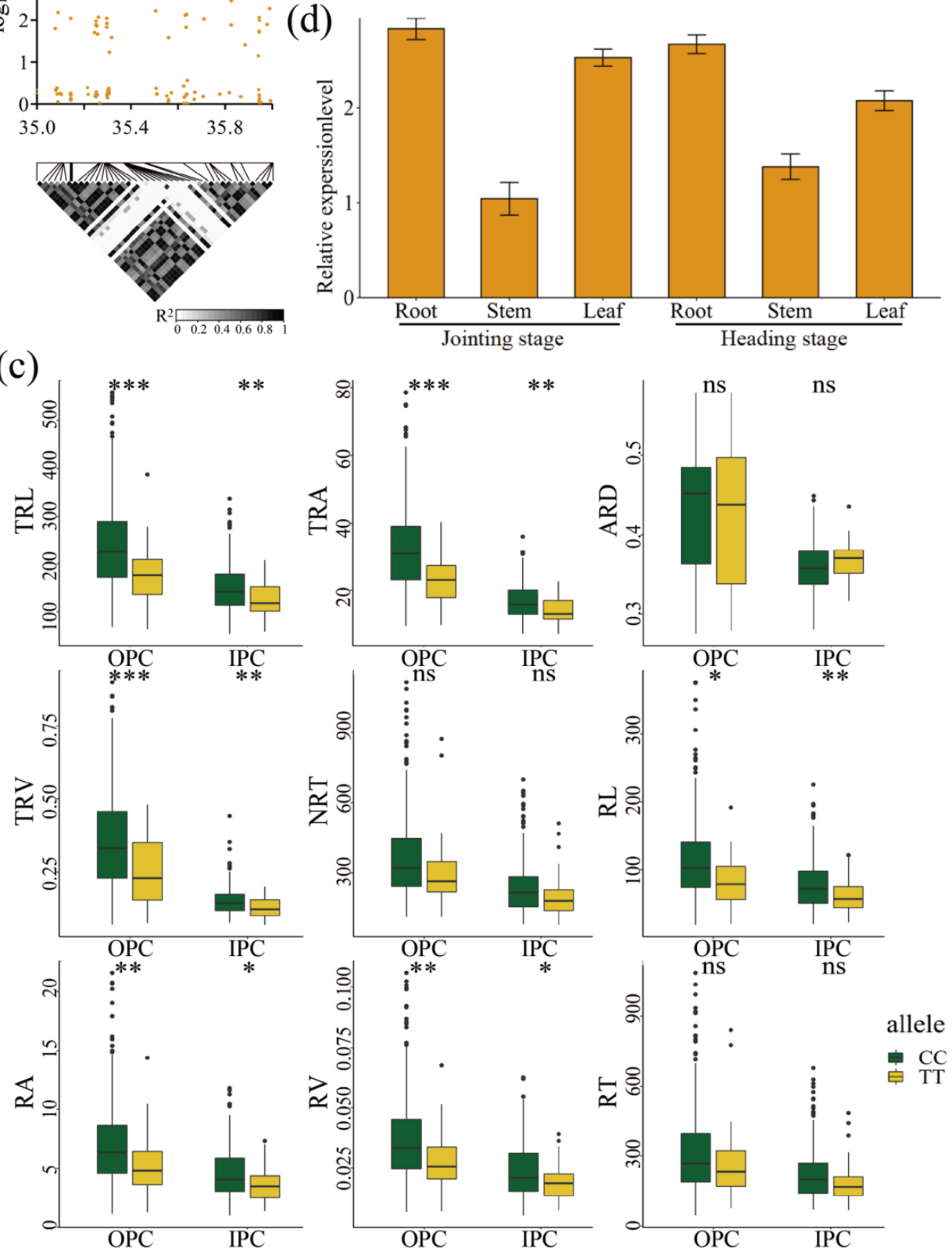

Figure 6. GWAS results of the nine RSA traits and identification of the candidate gene for the SNP AX-112287343 on chromosome 7B. (a) Manhattan plot for the candidate region on chromosome 7B. The green dot represents the significant SNP AX-112287343. The LD block analysis of the SNPs in this region is shown below. The degree of linkage is represented by the coefficient of $r^{2}$. (b) Gene structure of TraesCS7B01G036900 and its non-synonymous SNP. Yellow rectangles and black lines represent exons and introns, respectively. The arrow indicates the position of amino acid variations in TraesCS7B01G036900. (c) Box plots for RSA traits based on the allele at SNP AX-112287343. Differences between the haplotypes were statistically analysed using the Student's $t$-test. The upper and lower edges of the box represent the 75th and 25th quantiles, respectively, and the whiskers show the 90th and 10th quantiles; the horizontal solid line represents the average; * Significant at $p \leq 0.05$, ** Significant at $p \leq 0.01,{ }^{* * *}$ Significant at $p \leq 0.001$. (d) Expression profile of TraesCS7B01G036900 in different tissues, as determined by RT-qPCR. The data are the means $\pm \mathrm{Sd}$ of $n=3$. 'ns' means 'not significant'. 


\section{Discussion}

\subsection{Soil Culture and 660K SNp Chip Are Ideal Methods for GWAS of RSA Traits in Wheat}

Bread wheat is a staple crop worldwide, whose RSA traits strongly affect crop development and yield [49]. The spatial distribution of roots affects the absorption of water and nutrients and plant development. Zhu et al. [50] established that the length and number of seminal roots are particularly vital for the uptake of immobile nutrients. Devaiah et al. [51] found that the differences between RSA traits lead to changes in nutrient absorption. In addition, a deeper root system has higher water absorption capacity owing to its better access to soil water [52]. More importantly, White et al. [53] indicated that shoot and root architectures are inherited independently, and could be improved to increase the absorption and utilisation of water and nutrients. Therefore, it is important to analyse the RSA traits and explore the QTLs for these characteristics for further screening of key genes.

Some studies have identified several QTLs for RSA traits in wheat. To conveniently obtain whole roots, plants were usually cultivated in Hoagland's nutrient solution, sand, or agarose gel $[45,54]$. Hydroponics is the most common approach used to obtain the whole roots in wheat [22,31,32,42]. Although the QTLs for RSA traits that were identified through hydroponic cultivation coincided with those for yield and nutrient absorption in wheat $[43,44,55]$, we were not sure whether the phenotype of RSA traits in hydroponics was similar to that in soil cultivation. Therefore, soil cultivation is reliable to investigate RSA traits, although it is time-consuming and difficult. In this study, 388 wheat accessions were cultivated in soil under OPC and IPC, and the whole roots were sampled and cleaned up at the three-leaf stage to obtain the RSA traits for further analysis. The nine RSA traits showed high phenotypic variation at the seeding stage, indicating that the wheat panel used in this study exhibited high genetic diversity. The nine RSA traits under the two environments were significantly correlated, and the correlation between these RSA traits was significant, indicating that some QTLs may contribute to more than one RSA trait. The mean values of these RSA traits under OPC were significantly higher than those under IPC. We found that the soil under the two environments was comparable, and the mean temperature under IPC was higher than that under OPC. However, the root development was faster under OPC than that under IPC. It may be due to the climatic conditions from 15 October 2019 to 9 November 2019 that were optimal for wheat seedlings in Xinxiang $\left(35.29^{\circ} \mathrm{N}, 113.83^{\circ} \mathrm{E}\right)$, Henan, China. The broad-sense heritability of the nine RSA traits ranged from $66.78-77.83 \%$, indicating that these traits were suitable for QTL exploration.

Because of the vastness of genomic data, it is expensive to explore QTLs through genome re-sequencing in wheat. A series of high-density SNP chips, including 820K [56], 50K [57], 55K [58], 90K [33], and 660K chips, were designed and utilised for markerassisted breeding in bread wheat. The 660K SNP chip contains 229,266 SNPs in the gene or promoter regions of 66,834 genes, representing $63.52 \%$ of the annotated genes in wheat. It is an optimal chip for marker-assisted breeding and has been widely used for QTL exploration for quality traits, agronomic traits, and disease resistance in bread wheat [48]. In the present study, the wheat panel was genotyped for GWAS using the 660K SNP chip. It is reliable to screen for significant QTLs associated with RSA traits.

\subsection{QTL Analysis for RSA Traits}

A substantial number of studies have performed QTL mapping for RSA traits in different plants, of which 26 studies focused on RSA traits in wheat. They identified 410 QTLs for RSA traits (Table 5). In this study, 36 QTLs with a threshold of $-\log _{10}$ ( $p$-value) $\geq 4$ were identified for nine RSA traits. Among these, five QTLs overlapped with previously reported QTLs, and 31 new QTLs were identified. This indicates that these genomic regions for the RSA traits are reliable and provide new information for further studies. 
Table 5. Published studies on RSA traits and their chromosome localisations.

\begin{tabular}{|c|c|c|}
\hline Chr & Traits & Reference \\
\hline $1 \mathrm{~A}$ & $\begin{array}{l}\text { RGA, TRL, NRT, TRV, RHL, } \\
\text { MRL, TRA, ARD }\end{array}$ & {$[5,22,23,26,29,30,32,34,35,44,45]$} \\
\hline $1 \mathrm{~B}$ & $\begin{array}{c}\text { TRL, NRT, RHL, TRA, ARD, } \\
\text { TRV, MRL }\end{array}$ & {$[5,22,23,26,27,29,32,34-36,45]$} \\
\hline $1 \mathrm{D}$ & $\begin{array}{c}\text { NRT, TRA, TRL, ARD, NRT, } \\
\text { TRA }\end{array}$ & {$[28,30,32,37]$} \\
\hline $2 \mathrm{~A}$ & $\begin{array}{c}\text { TRL, TRV, ARD, TRA, NRT, } \\
\text { RGA, MRL }\end{array}$ & {$[5,23,30,32-38,44]$} \\
\hline 2B & $\begin{array}{c}\text { RGA, TRL, TRV, TRA, ARD, } \\
\text { NRT, MRL }\end{array}$ & {$[5,19,22-24,29-35,37,38,44,45]$} \\
\hline $2 \mathrm{D}$ & $\begin{array}{c}\text { TRL, RHL, TRV, TRA, ARD, } \\
\text { NRT, MRL }\end{array}$ & {$[22,24,26,31-33,37,45]$} \\
\hline $3 \mathrm{~A}$ & $\begin{array}{c}\text { RGA, TRL, NRT, RHL, MRL, } \\
\text { TRV, TRA, ARD }\end{array}$ & {$[5,22-24,26,30,32-36,43,45]$} \\
\hline 3B & $\begin{array}{c}\text { RGA, TRL, NRT, MRL, ARD, } \\
\text { TRV, TRA }\end{array}$ & {$[5,22-24,30,33-35,38,39,45]$} \\
\hline $3 \mathrm{D}$ & ARD, TRL, NRT & {$[32,38,39,45]$} \\
\hline $4 \mathrm{~A}$ & $\begin{array}{c}\text { RGA, TRL, NRT, TRV, TRA, } \\
\text { ARD }\end{array}$ & {$[22,23,25,28,30,32-35,37,38,42,45]$} \\
\hline $4 \mathrm{~B}$ & $\begin{array}{c}\text { TRL, NRT, ARD, TRA, RGA, } \\
\text { TRV }\end{array}$ & {$[5,22,23,28,30-32,34-37,39,42,43,45]$} \\
\hline $4 \mathrm{D}$ & TRL, TRA, NRT, MRL, TRV & {$[31,33,34,38]$} \\
\hline $5 \mathrm{~A}$ & $\begin{array}{c}\text { TRL, ARD, TRV, NRT, TRA, } \\
\text { MRL }\end{array}$ & {$[5,19,22,23,25,30,33-35,38,45]$} \\
\hline $5 \mathrm{~B}$ & $\begin{array}{c}\text { RGA, TRL, NRT, TRA, MRL, } \\
\text { TRV, TRA, ARD }\end{array}$ & {$[22,23,28-35,45,56,58]$} \\
\hline $5 \mathrm{D}$ & TRV, TRL, TRA, ARD, MRL & {$[22,28,29,32,34,37,45]$} \\
\hline $6 \mathrm{~A}$ & $\begin{array}{c}\text { RGA, NRT, MRL, TRL, ARD, } \\
\text { TRA }\end{array}$ & {$[5,22,23,29,31,34-36,44]$} \\
\hline $6 \mathrm{~B}$ & $\begin{array}{c}\text { RGA, TRL, NRT, MRL, RHL, } \\
\text { TRA, ARD, TRV }\end{array}$ & {$[5,19,22-24,26,29,34-36,39,43]$} \\
\hline $6 \mathrm{D}$ & $\begin{array}{c}\text { NRT, TRL, TRA, ARD, NRT, } \\
\text { MRL, RHL }\end{array}$ & {$[24,26,28,29,33,34,40,46]$} \\
\hline $7 \mathrm{~A}$ & $\begin{array}{c}\text { RGA, TRL, NRT, TRA, MRL, } \\
\text { ARD, TRV }\end{array}$ & {$[5,22-24,29-35,37,39-42,45]$} \\
\hline $7 \mathrm{~B}$ & $\begin{array}{l}\text { RGA, NRT, TRL, TRA, MRL, } \\
\text { ARD, RHL, TRV }\end{array}$ & {$[5,19,22-24,26,29-31,33-36,39,45]$} \\
\hline 7D & NRT, TRA, TRL, TRV, MRL & {$[22,29,30,32,34,37,38,40,45]$} \\
\hline
\end{tabular}

This study identified thirteen QTL clusters associated with more than one RSA trait that were distributed on ten chromosomes, indicating that there were co-localisations among these RSA traits. From the relationship among the nine RSA traits, we found that eight RSA traits showed significant positive correlations, and ARD showed a significant negative correlation with NRT, RL RA, RV, and RT in the two environments. From these results, we found that root traits are closely associated with each other, and some traits could be controlled by the same QTL. This might be because of the pleiotropic effects of the same gene or some RSA traits that might have a common genetic basis.

\subsection{QTL Analysis Reveals the Key Genes for RSA}

Key genes regulate RSA and root development. Therefore, the screening of key genes is important for RSA improvement. Zhang et al. [59] found that WOX4, encoded by AT1G46480, plays a central role in cambium development in Arabidopsis roots. Here, we found TraesCS2A01G514000, a homologue of AT1G46480, in the QTL on chromosome 2A, which was associated with TRA and TRV. Menand et al. [60] found that RHD6, encoded by AT1G66470, was a positive regulator for root hair development. TraesCS3B01G007700 was found to be homologous with AT1G66470 and mapped to the QTL of chromosome 
3B that was associated with NRT and RT. Bernhardt et al. [61] found that a GL3 protein, encoded by AT5G41315 in Arabidopsis, partially regulates root epidermal cell fates. Here, we found that TraesCS2D01G575600, a homologue of AT5G41315, was located in the QTL of chromosome 2D that was associated with ARD, which might influence root epidermal cell fate. Karas et al. [62] found that LRL1, encoded by AT2G24260, is a partial regulator of root hair development in Arabidopsis. Here, we found that TraesCS7D01G158300, a homologue of AT2G24260, was located in the QTL of chromosome 7D that was associated with ARD. Therefore, these genes were considered candidates for the respective RSA traits.

In addition, we manually screened the significant SNPs for haplotype analysis, and found that nine genes showed non-synonymous polymorphisms across the wheat panel. Two genes, TraesCS2A01G516200 (AX-110564036) and TraesCS7B01G036900 (AX-112287343), have attracted our attention. The different combinations of haplotypes for the two genes showed significant differences for RSA traits. Importantly, the two genes were highly expressed in the root tissues. Functional annotation analysis revealed that TraesCS2A01G516200 encoded a short-chain dehydrogenase/reductase and TraesCS7B01G036900 encoded a development and cell death domain protein. These results indicate that these two genes may be vital candidate genes for root architecture.

\section{Materials and Methods}

\subsection{Plant Materials and Experimental Treatment}

Based on pre-diversity assessment of more than 5000 wheat accessions using KASP markers or $660 \mathrm{~K}$ SNP chip, a diversity panel of 388 wheat accessions was collected, including 38 local landraces, 66 exotic cultivars, and 284 cross-derived cultivars in China. The name and origin of each wheat accession are listed in Table S1. Wheat seeds of uniform size were washed thrice with distilled water and germinated on wet filter papers in Petri dishes for germination at $20^{\circ} \mathrm{C}$. After 2 days, nine germinating seeds of each accession were evenly planted in one pot, and each pot was thinned to six seedlings after 10 days of sowing. Each pot (height $15 \mathrm{~cm}$; diameter $20 \mathrm{~cm}$ ) was filled with $4.5 \mathrm{~kg}$ of soil (nutritional soil: sieved tillage soil, $1: 1)$ to easily obtain the whole root system.

For OPC, the pots were randomly buried in a field on 15 October 2019 at Xinxiang $\left(35.29^{\circ} \mathrm{N}, 113.83^{\circ} \mathrm{E}\right)$, Henan, China. To facilitate management, 10 blocks were set in the field, each containing approximately 40 pots. The plants were watered to $70-80 \%$ of the field capacity. The seedlings developed to the three-leaf stage after 25 days of sowing with a mean temperature of $14.85^{\circ} \mathrm{C}$ and $0 \mathrm{~mm}$ of rainfall. For IPC, the pots were randomly placed in a phytotron. The seedlings were grown under $80 \%$ relative humidity, a $16 \mathrm{~h}$ light $\left(20{ }^{\circ} \mathrm{C}\right) / 8 \mathrm{~h}$ darkness $\left(18^{\circ} \mathrm{C}\right)$ photoperiod, and $8000 \mathrm{Lux}$ light intensity. The seedlings developed to the three-leaf stage after 30 days of sowing. The roots were cleaned with water. For each wheat accession under the two environments, six biological replications were sampled for further RSA trait measurement.

\subsection{RSA Trait Measurement}

The root samples were placed in plexiglass trays $(200 \mathrm{~mm} \times 250 \mathrm{~mm})$ containing 4-6 mm of distilled water. The roots were manipulated to minimise tangling and overlap. Nine RSA traits (Table 6), TRL, TRA, ARD, TRV, NRT, RL, RA, RV, and RT, were measured using a recording scanner (Epson 1680, Suwa, Japan). The images were analysed using Win RHIZO Pro Vision 5.0a (Regent Instruments Inc., Quebec, QC, Canada), which was operationally semi-automated. 
Table 6. Abbreviations for RSA traits and their units.

\begin{tabular}{ccc}
\hline Acronym & RSA Traits & Units \\
\hline TRL & Total root length & Centimetres $(\mathrm{cm})$ \\
TRA & Total root surface area & Square centimetres $\left(\mathrm{cm}^{2}\right)$ \\
ARD & Average root diameter & Millimetres $(\mathrm{mm})$ \\
TRV & Total root volume & Cubic centimetres $\left(\mathrm{cm}^{3}\right)$ \\
NRT & Number of root tips & Number $($ no. $)$ \\
RL & Root length (root diameter $\leq 0.3 \mathrm{~mm})$ & Centimetres $(\mathrm{cm})$ \\
RA & Root surface area (root diameter $\leq 0.3 \mathrm{~mm})$ & Square centimetres $\left(\mathrm{cm}^{2}\right)$ \\
RV & Root volume (root diameter $\leq 0.3 \mathrm{~mm})$ & Cubic centimetres $\left(\mathrm{cm}^{3}\right)$ \\
RT & Root tips (root diameter $\leq 0.3 \mathrm{~mm})$ & Number $(\mathrm{no})$. \\
\hline
\end{tabular}

\subsection{Phenotypic Data Analysis for RSA Traits}

SPSS (Version 17.0) and R packages (R Version 4.1.1) were used for data analysis. Genotype, environments, and genotype-by-environment interactions were considered as random effects in a linear mixed model (LMM_4 K). The lme4 package in the R 4.1.1 program was used to estimate the BLUPs. The $H^{2}$ of the RSA traits was calculated using the mean values of each experiment among six replications using the formula:

$$
H^{2}=\frac{\sigma_{G}^{2}}{\sigma_{G}^{2}+\frac{\sigma_{G E}^{2}}{n}+\frac{\sigma_{e}^{2}}{n r}}
$$

where $\sigma_{G}^{2}$ is the genetic variance, $\sigma_{G E}^{2}$ is the genotype $\times$ environment, $\sigma_{e}^{2}$ is the error variance, $n$ represents the number of environments, and $r$ represents the number of replications. The mean values were used to analyse the differences using a $t$-test. The $C V$ was calculated for all the RSA traits [63].

\subsection{Population Structure}

Principal component analysis of the population was performed using the GCTA software [64]. For population structure analysis, a Bayesian model-based (Markov Chain Monte Carlo) clustering approach was used in the STRUCTURE software v2.3.4 with unlinked markers $\left(r^{2}=0\right)$ [65]. The $K$-value, representing the number of subgroups, was set from 2 to 20, and five independent runs for each $K$ were performed with the burn-in length set to 20,000 and iterations set to 10,000. The most likely number of subpopulations was determined using the $\Delta K$ method based on the rate of change in LnP (D) between successive K-values [66].

\subsection{LD Analysis}

Genome-wide LD analysis for the A, B, and D genomes was performed using the PLINK software. The squared allele-frequency correlations $\left(r^{2}\right)$ were used to estimate the LD by applying pair-wise comparisons among the filtered SNP markers. The values for genomes $\mathrm{A}, \mathrm{B}$, and $\mathrm{D}$ were plotted against the genetic distance to determine $\mathrm{LD}$ decay. The parameters for calculating $r^{2}$ were set to -r2 -ld-window-kb 30000 -ld-window 1000 -ld-window-r2 0. A locally weighted polynomial regression (LOESS) curve was drawn to fit the data using second-order local weighted scatter plot smoothing in the R program. The critical distance spanning the QTL was defined based on the intersection point of the fitted LOESS curve with the LD $\left(r^{2}=0.1\right)$.

\subsection{Genotyping Data Using 660K SNp Chip}

The wheat panel was genotyped using the Affymetrix Wheat 660K SNP Chip [48], which was provided by the Beijing CapitalBio Technology Company (http:/ / www.capitalbiotech.com, accessed on 8 January 2022). SNP genotyping calling and allele clustering were performed using the polyploid version of the Affymetrix Genotyping Console software. To ensure genotyping accuracy, quality control, and filtering of raw data with missing data $>10 \%$, a minor allele 
frequency $<5 \%$, or Hardy-Weinberg Equilibrium $>0.01$ were performed. The remaining high-quality SNP markers were used for GWAS. The sequence of each polymorphic SNP was identified using Basic Local Alignment Search Tool (BLAST)n 2.2.29+, and the physical positions of all SNPs were determined by blasting them with the wheat reference genome IWGSC RefSeq v1.0. The parameters of the blast result were set to: ratio (AL/QL) $\geq 0.95$, identity $\geq 0.95$, and E-value $<1 \times \mathrm{e}^{-10}$. Two genetic diversity parameters, PIC and $\mathrm{He}$, were calculated for each SNP marker and each chromosome using the formulas described by Botsteinet et al. [67] and Nei [68], respectively.

\subsection{GWAS}

GWAS was conducted using a univariate linear mixed model in the GEMMA software [69]. The suggestive threshold for $p$-value $(p=1 / \mathrm{Ne})$ was calculated using a modified Bonferroni correction (genetic type 1 Error calculator, version 0.2), where Ne represents the effective number of SNP markers [70]. A threshold was established at $-\log _{10} p \geq 4$ to determine the marker-trait association significance. Moreover, the $p$-value of $-\log _{10} p \geq 3.5$ was used to establish a second, less restrictive threshold. Significant markers from GWAS were visualised in Manhattan plots, and important $p$-value distributions were visualised using quantile-quantile (Q-Q) plots drawn with the qqman package in $\mathrm{R}$ 4.1.1. The phenotypic variance $\left(R^{2}\right)$ explained by significant SNPs was evaluated using the GCTA software [64].

\subsection{Candidate Gene Identification, RNA Extraction, and RT-qPCR Verification}

Candidate genes were selected using functional annotation and haplotype analysis. For haplotype analysis, the significant SNPs in QTL clusters were used to identify nonsynonymous polymorphisms. The phenotypic differences between the haplotypes of the nine RSA traits were analysed to identify the candidate genes.

The root, stem, and leaf tissues were sampled from wheat plants of cv. Chinese Spring grown in the field at the jointing and heading stages, respectively. The total RNA was extracted using the TRIzol reagent (TaKaRa, Ohtsu, Japan) according to the manufacturer's instructions. One microgram of the total RNA was used for first-strand cDNA synthesis using the HiScript III First-Strand cDNA Synthesis Kit (Vazyme, Nanjing, China). qPCR was performed on an ABI 7500 real-time PCR system (Applied Biosystems, Forest City, CA, USA) using SYBR Premix Ex Taq Kit (TaKaRa, Japan). Three biological replications were used for each experiment. TaActin3 was used as an internal control [71], and the relative expression value was calculated using the $2^{-\Delta \Delta \mathrm{Ct}}$ method. All primers used for RT-qPCR were listed in Table S6.

Supplementary Materials: The following supporting information can be downloaded at: https: //www.mdpi.com/article/10.3390/ijms23031843/s1.

Author Contributions: Conceptualization, J.M., T.L. and L.J.; investigation, J.M., D.Z. (Dongyang Zhao), X.T., M.Y., D.Z. (Daijing Zhang), M.X., Y.D. and H.R.; writing—original draft preparation, J.M., Q.Z., J.W. and D.H.; writing-review and editing, J.M., T.L. and L.J. All authors have read and agreed to the published version of the manuscript.

Funding: This research was funded by the National Key Research and Development Program of China (2017YFD0301101 and 2016YFD0300203-3).

Institutional Review Board Statement: Not applicable.

Informed Consent Statement: Not applicable.

Data Availability Statement: Not applicable.

Conflicts of Interest: The authors declare no conflict of interest. 


\section{References}

1. Ray, D.K.; Mueller, N.D.; West, P.C.; Foley, J.A. Yield Trends Are Insufficient to Double Global Crop Production by 2050. PLoS ONE 2013, 8, e66428. [CrossRef] [PubMed]

2. Sharma, I.; Tyagi, B.S.; Singh, G.; Venkatesh, K.; Gupta, O.P. Enhancing wheat production-A global perspective. Indian J. Agric. Sci. 2015, 85, 3-13.

3. Wheeler, T.; Braun, J.V. Climate Change Impacts on Global Food Security. Science 2013, 341, 508-513. [CrossRef] [PubMed]

4. Zampieri, M.; Ceglar, A.; Dentener, F.; Toreti, A. Wheat yield loss attributable to heat waves, drought and water excess at the global, national and subnational scales. Environ. Res. Lett. 2017, 12, 064008. [CrossRef]

5. Maccaferri, M.; El-Feki, W.; Nazemi, G.; Salvi, S.; Canè, M.A.; Colalongo, M.C.; Stefanelli, S.; Tuberosa, R. Prioritizing quantitative trait loci for root system architecture in tetraploid wheat. J. Exp. Bot. 2016, 67, 1161-1178. [CrossRef]

6. Atkinson, J.A.; Pound, M.P.; Bennett, M.J.; Wells, D.M. Uncovering the hidden half of plants using new advances in root phenotyping. Curr. Opin. Biotechnol. 2019, 55, 1-8. [CrossRef]

7. Li, X.K.; Guo, Z.L.; Lv, Y.; Cen, X.; Ding, X.P.; Wu, H.; Li, X.H.; Huang, J.P.; Xiong, L.Z. Genetic control of the root system in rice under normal and drought stress conditions by genome-wide association study. PLOS Genet. 2017, 13, e1006889. [CrossRef]

8. Chen, X.X.; Ding, Q.S.; Błaszkiewicz, Z.; Sun, J.A.; Sun, Q.; He, R.Y.; Li, Y.N. Phenotyping for the dynamics of field wheat root system architecture. Sci. Rep. 2017, 7, 37649. [CrossRef]

9. Huang, C.Y.; Kuchel, H.; Edwards, J.; Hall, S.; Parent, B.; Eckermann, P.; Herdina; Hartley, D.M.; Langridge, P.; McKay, A.C. A DNA-based method for studying root responses to drought in field-grown wheat genotypes. Sci. Rep. 2013, 3, 3194. [CrossRef]

10. Manschadi, A.M.; Hammer, G.L.; Christopher, J.T.; Devoil, P. Genotypic variation in seedling root architectural traits and implications for drought adaptation in wheat (Triticum aestivum L.). Plant Soil 2008, 303, 115-129. [CrossRef]

11. Voss-Fels, K.P.; Qian, L.; Parra-Londono, S.; Uptmoor, R.; Frisch, M.; Keeble-Gagnère, G.; Apples, R.; Snowdon, R.J. Linkage drag constrains the roots of modern wheat. Plant Cell Environ. 2017, 40, 717-725. [CrossRef] [PubMed]

12. Man, J.; Shi, Y.; Yu, Z.; Zhang, Y. Dry Matter Production, Photosynthesis of Flag Leaves and Water Use in Winter Wheat Are Affected by Supplemental Irrigation in the Huang-Huai-Hai Plain of China. PLoS ONE 2015, 10, e0137274. [CrossRef] [PubMed]

13. Wasaya, A.; Zhang, X.Y.; Fang, Q.; Yan, Z.Z. Root Phenotyping for Drought Tolerance: A Review. Agronomy 2018, 8, 241. [CrossRef]

14. Christopher, J.; Christopher, M.; Jennings, R.; Jones, S.; Fletcher, S.; Borrell, A.; Manschadi, B.A.; Jordan, D.; Mace, E.; Hammer, G. QTL for root angle and number in a population developed from bread wheats (Triticum aestivum) with contrasting adaptation to water-limited environments. Theor. Appl. Genet. 2013, 126, 1563-1574. [CrossRef] [PubMed]

15. Bai, C.H.; Liang, Y.L.; Hawkesford, M.J. Identification of QTLs associated with seedling root traits and their correlation with plant height in wheat. J. Exp. Bot. 2013, 64, 1745-1753. [CrossRef]

16. Zhang, W.P.; Shen, X.Y.; Wu, P.; Hu, B.; Liao, C.Y. QTLs and epistasis for seminal root length under a different water supply in rice (Oryza sativa L.). Theor. Appl. Genet. 2001, 103, 118-123. [CrossRef]

17. Li, P.C.; Fan, Y.Y.; Yin, S.Y.; Wang, Y.Y.; Wang, H.M.; Xu, Y.; Yang, Z.F.; Xu, C.W. Multi-environment QTL mapping of crown root traits in a maize RIL population. Crop J. 2020, 8, 645-654. [CrossRef]

18. Wu, Y.D.; Zhang, S.F.; Zhang, H.; Li, F.; Li, G.L.; Fan, C.C.; Sun, R.F.; Zhang, S.J. QTL mapping and candidate gene identification of swollen root formation in Turnip. Int. J. Mol. Sci. 2021, 22, 653. [CrossRef]

19. Ren, Y.; Qian, Y.; Xu, Y.; Zou, C.; Liu, D.; Zhao, X.; Zhang, A.; Tong, Y. Characterization of QTLs for Root Traits of Wheat Grown under Different Nitrogen and Phosphorus Supply Levels. Front. Plant Sci. 2017, 8, 2096. [CrossRef]

20. Steele, K.A.; Price, A.H.; Witcombe, J.R.; Shrestha, R.; Singh, B.N.; Gibbons, J.M.; Virk, D.S. QTLs associated with root traits increase yield in upland rice when transferred through marker-assisted selection. Theor. Appl. Genet. 2012, 126, 101-108. [CrossRef]

21. Li, C.N.; Li, L.; Reynolds, M.P.; Wang, J.Y.; Chang, X.P.; Mao, X.G.; Jing, R.L. Recognizing the hidden half in wheat: Root system attributes associated with drought tolerance. J. Exp. Bot. 2021, 72, 5117-5133. [CrossRef] [PubMed]

22. Liu, P.; Jin, Y.R.; Liu, J.D.; Liu, C.Y.; Yao, H.P.; Luo, F.Y.; Guo, Z.H.; Xia, X.C.; He, Z.H. Genome-wide association mapping of root system architecture traits in common wheat (Triticum aestivum L.). Euphytica 2019, 215, 121. [CrossRef]

23. Alemu, A.; Feyissa, T.; Maccaferri, M.; Sciara, G.; Tuberosa, R.; Ammar, K.; Badebo, A.; Acevedo, M.; Letta, L.; Abeyo, B. Genome-wide association analysis unveils novel QTLs for seminal root system architecture traits in Ethiopian durum wheat. BMC Genom. 2021, 22, 20. [CrossRef] [PubMed]

24. Fan, X.L.; Zhang, W.; Zhang, N.; Chen, M.; Zheng, S.S.; Zhao, C.H.; Han, J.; Liu, J.J.; Zhang, X.L.; Song, L.Q.; et al. Identification of QTL regions for seedling root traits and their effect on nitrogen use efficiency in wheat (Triticum aestivum L.). Theor. Appl. Genet. 2018, 131, 2677-2698. [CrossRef]

25. Salarpour, M.; Pakniyat, H.; Abdolshahi, R.; Heidari, B.; Razi, H.; Afzali, R. Mapping QTL for agronomic and root traits in the Kukri/RAC875 wheat (Triticum aestivum L.) population under drought stress conditions. Euphytica 2020, 216, 105. [CrossRef]

26. Huang, F.; Chen, Z.Y.; Du, D.J.; Guan, P.F.; Chai, L.L.; Guo, W.L.; Hu, Z.R.; Xin, M.M.; Peng, H.R.; Yao, Y.Y.; et al. Genome-wide linkage mapping of QTL for root hair length in a Chinese common wheat population. Crop J. 2020, 8, 1049-1056. [CrossRef]

27. Yang, M.J.; Wang, C.R.; Hassan, M.A.; Li, F.J.; Xia, X.C.; Shi, S.B.; Xiao, Y.G.; He, Z.H. QTL mapping of root traits in wheat under different phosphorus levels using hydroponic culture. BMC Genom. 2021, 22, 174. [CrossRef] 
28. Xu, F.D.; Chen, S.L.; Yang, X.W.; Zhou, S.M.; Wang, J.S.; Zhang, Z.L.; Huang, Y.; Song, M.; Zhang, J.; Zhan, K.H.; et al. GenomeWide Association Study on Root Traits Under Different Growing Environments in Wheat (Triticum aestivum L.). Front. Genet. 2021, 12, 646712. [CrossRef]

29. Li, Z.X.; Ni, Z.F.; Peng, H.R.; Liu, Z.Y.; Nie, X.L.; Xu, S.B.; Liu, G.; Sun, Q.X. Molecular mapping of QTLs for root response to phosphorus deficiency at seedling stage in wheat (Triticum aestivum L.). Prog. Nat. Sci. 2007, 17, 1177-1184.

30. Yang, M.J.; Wang, C.R.; Hassan, M.A.; Wu, Y.Y.; Xia, X.C.; Shi, S.B.; Xiao, Y.G.; He, Z.H. QTL mapping of seedling biomass and root traits under different nitrogen conditions in bread wheat (Triticum aestivum L.). J. Integr. Agric. 2021, 20, 1180-1192. [CrossRef]

31. Li, T.; Ma, J.; Zou, Y.Y.; Chen, G.D.; Ding, P.Y.; Zhang, H.; Lan, X.J. Quantitative trait loci for seeding root traits and the relationships between root and agronomic traits in common wheat. Genome 2019, 63, 27-36. [CrossRef]

32. Zheng, X.W.; Wen, X.J.; Qiao, L.; Zhao, J.J.; Zhang, X.J.; Li, X.; Zheng, J. A novel QTL QTrl.saw-2D.2 associated with the total root length identified by linkage and association analyses in wheat (Triticum aestivum L.). Planta 2019, 250, 129-143. [CrossRef]

33. Kabir, M.R.; Liu, G.; Guan, P.; Wang, F.; Khan, A.A.; Ni, Z.; Sun, Q. Mapping QTLs associated with root traits using two different populations in wheat (Triticum aestivum L.). Euphytica 2015, 206, 175-190. [CrossRef]

34. Soriano, J.M.; Alvaro, F. Discovering consensus genomic regions in wheat for root-related traits by QTL meta-analysis. Sci. Rep. 2019, 9, 10537. [CrossRef] [PubMed]

35. Roselló, M.; Royo, C.; Sanchez-Garcia, M.; Soriano, J.M. Genetic Dissection of the Seminal Root System Architecture in Mediterranean Durum Wheat Landraces by Genome-Wide Association Study. Agronomy 2019, 9, 364. [CrossRef]

36. Iannucci, A.; Marone, D.; Russo, M.A.; De Vita, P.; Miullo, V.; Ferragonio, P.; Mastrangelo, A.M. Mapping QTL for Root and Shoot Morphological Traits in a Durum Wheat $\times$ T. dicoccum Segregating Population at Seedling Stage. Int. J. Genom. 2017, 2017, 1-17. [CrossRef] [PubMed]

37. Ibrahim, S.E.; Schubert, A.; Pillen, K.; Léon, J. QTL analysis of drought tolerance for seedling root morphological traits in an advanced backcross population of spring wheat. Int. J. Agric. Sci. 2012, 2, 619-629.

38. Xie, Q.; Fernando, K.M.C.; Mayes, S.; Sparkes, D.L. Identifying seedling root architectural traits associated with yield and yield components in wheat. Ann. Bot. 2017, 119, 1115-1129. [CrossRef] [PubMed]

39. Ma, J.; Luo, W.; Zhang, H.; Zhou, X.H.; Qin, N.N.; Wei, Y.M.; Liu, Y.X.; Jiang, Q.T.; Lan, X.J. Identification of quantitative trait loci for seedling root traits from Tibetan semi-wild wheat (Triticum aestivum subsp. tibetanum). Genome 2017, 60, 1068-1075. [CrossRef] [PubMed]

40. Atkinson, J.A.; Wingen, L.U.; Griffiths, M.; Pound, M.P.; Gaju, O.; Foulkes, M.J.; Wells, D.M. Phenotyping pipeline reveals major seedling root growth QTL in hexaploid wheat. J. Exp. Bot. 2015, 66, 2283-2292. [CrossRef]

41. Merchuk-Ovnat, L.; Fahima, T.; Ephrath, J.E.; Krugman, T.; Saranga, Y. Ancestral QTL Alleles from Wild Emmer Wheat Enhance Root Development under Drought in Modern Wheat. Front. Plant Sci. 2017, 8, 1-12. [CrossRef] [PubMed]

42. Halder, T.; Liu, H.; Chen, Y.L.; Yan, G.J.; Siddique, K.H. Identification of Candidate Genes for Root Traits Using GenotypePhenotype Association Analysis of Near-Isogenic Lines in Hexaploid Wheat (Triticum aestivum L.). Int. J. Mol. Sci. 2021, $22,3579$. [CrossRef]

43. Canè, M.A.; Maccaferri, M.; Nazemi, G.; Salvi, S.; Francia, R.; Colalongo, C.; Tuberosa, R. Association mapping for root architectural traits in durum wheat seedlings as related to agronomic performance. Mol. Breed. 2014, 34, 1629-1645. [CrossRef] [PubMed]

44. Horn, R.; Wingen, L.U.; Snape, J.W.; Dolan, L. Mapping of quantitative trait loci for root hair length in wheat identifies loci that co-locate with loci for yield components. J. Exp. Bot. 2016, 67, 4535-4543. [CrossRef] [PubMed]

45. Liu, X.L.; Li, R.Z.; Chang, X.P.; Jing, R.L. Mapping QTLs for seedling root traits in a doubled haploid wheat population under different water regimes. Euphytica 2012, 189, 51-66. [CrossRef]

46. Kai, V.F.; Robinson, H.; Mudge, S.R.; Richard, C.; Hickey, L.T. Vernalization1 modulates root system architecture in wheat and barley. Mol. Plant 2018, 11, 226. [CrossRef]

47. Wang, J.; Li, L.; Li, C.; Yang, X.; Xue, Y.; Zhu, Z.; Mao, X.; Jing, R. A transposon in the vacuolar sorting receptor gene TaVSR1-B promoter region is associated with wheat root depth at booting stage. Plant Biotechnol. J. 2021, 19, 1456-1467. [CrossRef]

48. Sun, C.W.; Dong, Z.D.; Zhao, L.; Ren, Y.; Zhang, N.; Chen, F. The Wheat 660K SNP array demonstrates great potential for marker-assisted selection in polyploid wheat. Plant Biotechnol. J. 2020, 18, 1354-1360. [CrossRef]

49. Fang, C.; Ma, Y.M.; Wu, S.W.; Liu, Z.; Wang, Z.; Yang, R.; Hu, G.H.; Zhou, Z.K.; Yu, H.; Tian, Z.X. Genome-wide association studies dissect the genetic networks underlying agronomical traits in soybean. Genome Biol. 2017, 18, 1-4. [CrossRef]

50. Zhu, J.; Mickelson, S.M.; Kaeppler, S.M.; Lynch, J.P. Detection of quantitative trait loci for seminal root traits in maize (Zea mays L.) seedlings grown under differential phosphorus levels. Theor. Appl. Genet. 2006, 113, 1-10. [CrossRef]

51. Devaiah, B.N.; Nagarajan, V.K.; Raghothama, K.G. Phosphate Homeostasis and Root Development in Arabidopsis Are Synchronized by the Zinc Finger Transcription Factor ZAT6. Plant Physiol. 2007, 145, 147-159. [CrossRef]

52. Tambussi, E.A.; Bort, J.; Araus, J.L. Water use efficiency in C3 cereals under Mediterranean conditions: A review of physiological aspects. Ann. Appl. Biol. 2007, 150, 307-321. [CrossRef]

53. White, P.J. Root traits benefitting crop production in environments with limited water and nutrient availability. Ann. Bot. 2019, 124, 883-890. [CrossRef]

54. Ayalew, H.; Desalegn, T.; Hui, L.; Yan, G. Performance of Ethiopian bread wheat (Tritium aestivum L.) genotypes under contrasting water regimes: Potential sources of variability for drought resistance breeding. Aust. J. Crop Sci. 2016, 10, 370-376. [CrossRef] 
55. An, D.G.; Su, J.Y.; Liu, Q.Y.; Li, B.; Jing, R.L.; Li, B.; Li, Z.Z. Mapping QTLs for nitrogen uptake in relation to the early growth of wheat (Triticum aestivum L.). Plant Soil 2006, 284, 73-84. [CrossRef]

56. Winfield, M.O.; Allen, A.M.; Burridge, A.J.; Barker, G.L.A.; Benbow, H.R.; Wilkinson, P.A.; Edwards, K.J. High-density SNP genotyping array for hexaploid wheat and its secondary and tertiary gene pool. Plant Biotechnol. J. 2015, 14, 1195-1206. [CrossRef]

57. Rasheed, A.; Hao, Y.F.; Xia, X.C.; Khan, A.; Xu, Y.B.; Varshney, R.K.; He, Z.H. Crop Breeding Chips and Genotyping Platforms: Progress, Challenges, and Perspectives. Mol. Plant 2017, 10, 1047-1064. [CrossRef]

58. Ye, X.L.; Li, J.; Cheng, Y.K.; Yao, F.J.; Long, L.; Wang, Y.Q.; Chen, G.Y. Genome-wide association study reveals new loci for yield-related traits in Sichuan wheat germplasm under stripe rust stress. BMC Genom. 2019, 20, 640. [CrossRef]

59. Zhang, J.; Eswaran, G.; Alonso-Serra, J.; Kucukoglu, M.; Xiang, J.; Yang, W.; Helariutta, Y. Transcriptional regulatory framework for vascular cambium development in Arabidopsis roots. Nat. Plants 2019, 5, 1033-1042. [CrossRef]

60. Menand, B.; Yi, K.; Jouannic, S.; Hoffmann, L.; Ryan, E.; Linstead, P.; Dolan, L. An Ancient Mechanism Controls the Development of Cells with a Rooting Function in Land Plants. Science 2007, 316, 1477-1480. [CrossRef]

61. Bernhardt, C. The bHLH genes GLABRA3 (GL3) and ENHANCER OF GLABRA3 (EGL3) specify epidermal cell fate in the Arabidopsis root. Development 2003, 130, 6431-6439. [CrossRef]

62. Karas, B.; Amyot, L.; Johansen, C.; Sato, S.; Tabata, S.; Kawaguchi, M.; Szczyglowski, K. Conservation of Lotus and Arabidopsis Basic Helix-Loop-Helix Proteins Reveals New Players in Root Hair Development. Plant Physiol. 2009, 151, 1175-1185. [CrossRef]

63. Nyquist, W.E.; Baker, R.J. Estimation of heritability and prediction of selection response in plant populations. Crit. Rev. Plant Sci. 1991, 10, 235-322. [CrossRef]

64. Yang, J.; Lee, S.H.; Goddard, M.E.; Visscher, P.M. GCTA: A Tool for Genome-wide Complex Trait Analysis. Am. J. Hum. Genet. 2011, 88, 76-82. [CrossRef]

65. Pritchard, J.K.; Stephens, M.; Donnelly, P. Inference of Population Structure Using Multilocus Genotype Data. Genetics 2000, 155, 945-959. [CrossRef]

66. Earl, D.A.; VonHoldt, B.M. STRUCTURE HARVESTER: A website and program for visualizing STRUCTURE output and implementing the Evanno method. Conserv. Genet. Resour. 2011, 4, 359-361. [CrossRef]

67. Botstein, D.; White, R.L.; Skolnick, M.; Davis, R.W. Construction of a genetic linkage map in man using restriction fragment length polymorphisms. Am. J. Hum. Genet. 1980, 32, 314. [CrossRef]

68. Nei, M. Estimation of average heterozygosity and genetic distance from a small number of individuals. Genetics 1978, 89, 583-590. [CrossRef]

69. Zhou, X.; Stephens, M. Genome-wide efficient mixed-model analysis for association studies. Nat. Genet. 2012, 44, 821-824. [CrossRef]

70. Li, M.X.; Yeung, J.M.Y.; Cherny, S.S.; Sham, P.C. Evaluating the effective numbers of independent tests and significant $p$-value thresholds in commercial genotyping arrays and public imputation reference datasets. Hum. Genet. 2011, 131, 747-756. [CrossRef]

71. Wang, X.; Ren, Y.; Li, J.; Wang, Z.; Xin, Z.; Lin, T. Knock-down the expression of TaH2B-7D using virus-induced gene silencing reduces wheat drought tolerance. Biol. Res. 2019, 52, 14. [CrossRef] [PubMed] 